\title{
The Power of Customer Choice in Energy: A California Case Study in Accelerating Clean Energy Transitions
}

\author{
Kelly Trumbull, J.R. DeShazo
}

University of California Los Angeles, Luskin Center for Innovation, Los Angeles, California https://doi.org/10.38126/ISPG180211

Corresponding author: ktrumbull@luskin.ucla.edu

Keywords: community choice aggregation; carbon free electricity; investor-owned utilities; renewable energy; renewables portfolio standard

Executive Summary: Despite a lack of action at the national level, the transition to carbonfree energy is becoming a reality across the United States. At the local level, community choice aggregators (CCAs) - which offer communities public control over their electricity purchasing decisions-are accelerating this transition. By forming these electricity providers, member cities and counties can choose how much renewable energy is offered to their residents and businesses.

In California, CCAs have become an effective policy tool at accelerating the transition to clean energy. Across the state, 182 cities and counties have become members of one of the 23 CCAs, with additional communities planning to join or form CCAs in the next few years. These CCAs have been effective at unlocking market demand largely stifled by an investor-owned utility monopoly by giving cities and counties greater choice and access to renewable energy. The vast majority of these CCAs procure more renewable energy than the investor-owned utilities they compete with. As a result, CCAs purchased 204\% of the renewable energy required by the state from 2011 to 2019. By achieving California's carbon-free energy targets more quickly than mandated, the state benefits from a cumulatively larger reduction in greenhouse gas emissions each year. The success of CCAs in California demonstrates the power of promoting carbon-free energy at the grassroots, enabled by public, local choice in electricity supply.

With six states considering CCA-enabling legislation, and with hundreds of cities and counties across the United States working toward a 100\% carbon-free energy goal, policies like California Assembly Bill 117 (2002) that enabled CCAs can provide a valuable tool to accelerate the transition to carbon-free energy. The purpose of this paper is to assess how CCA-enabling policy can support the clean energy transition using California as a case study. We assess three conditions that affect a CCA's ability to accelerate the clean energy transition: CCA customer characteristics, CCA design features, and their policy and regulatory context. We conclude with a discussion of policy recommendations important to ensure CCAs can continue to support clean energy goals.

\section{Customer choice in electricity accelerates clean energy}

Increasingly, communities across the United States are gaining control over decisions regarding the electricity they buy. One method to do so is through community choice aggregation (CCA), a policy tool enabled by California Assembly Bill 117 (2002) that allows cities and counties to purchase electricity on behalf of their residents. Locally focused by design, a CCA makes electricity purchasing decisions to reflect its community's preferences. In practice, this means that CCAs often purchase electricity from cleaner 
electricity sources (i.e., those that emit fewer greenhouse gases) than those provided by alternative electricity providers (O'Shaughnessy et al. 2019a).

The primary way CCAs support environmental goals is through the purchase of carbon-free energy. ${ }^{1}$ In California one powerful tool for CCAs is their ability to choose how much carbon-free electricity a customer receives by default. Fourteen California CCA member communities chose $100 \%$ renewable energy as the default for all their customers. Furthermore, this paper finds that over two-thirds of California CCA member communities-representing more than 6 million people-have a default electricity product with more than $90 \%$ carbon-free energy.

CCAs in California have accelerated the achievement of the state's carbon-free energy targets. In this paper, we examine how the policy that enabled CCAs has been effective at accelerating the transition to clean energy. We first give an overview of existing CCAs across the U.S. and their contribution to renewable energy goals. Next, we calculate the extent to which the proliferation of CCA has resulted in advancing California's renewable energy goals and demonstrate that CCAs have had both direct and indirect effects that contributed to exceeding the state's renewables portfolio standard requirements, thereby accelerating the carbon-free energy transition. We then examine three conditions that have enabled California CCAs to be an effective tool to support this clean energy transition: 1) customer characteristics, 2) CCA design features, and 3) policy and regulatory context. We conclude with a discussion about how future over compliance with renewables requirements is dependent on ambitious state renewable energy policies, regulation, and CCAs' actions and provide recommendations important to ensure CCAs can continue to support clean energy goals into the future.

\section{Background: CCAs across the United States}

\section{i. A National Overview of CCAs and Their Contribution to Renewable Energy}

CCAs allow local governments to make decisions about the type and location of electricity resources purchased on behalf of their residents, businesses, and municipal facilities. Currently, nine states have CCA-enabling legislation, with six more considering (Lean Energy U.S. 2020). ${ }^{2}$ While CCAs vary significantly in size and electricity products offered, CCAs across all states have common features, including:

- CCA creation and operation decisions are made by local elected officials, often at the city or county level.

- CCAs purchase electricity for customers, while private investor-owned utilities (IOUs) continue to provide electricity transmission, distribution, metering, and billing services.

- When a CCA launches, a community's customers are automatically enrolled, but they can choose to opt out of its service and remain with the incumbent electricity provider.

A community may choose to form or join a CCA for a number of reasons, including for the following advantages of CCAs identified by the U.S. Environmental Protection Agency (U.S. Environmental Protection Agency 2020):

- Electricity rate reduction

- Shift to greener energy resources

- Ability to respond to local economic and environmental goals through control of electricity generation

- Expansion of consumer choice

- Support of local jobs and renewable energy development

As inherently local, public entities, CCAs are designed with input from their communities, are operated with ongoing community input on decision-making, and as such, reflect the preferences of their communities.

\footnotetext{
${ }^{1}$ In this paper, we refer to carbon-free energy resources as those that include renewable energy resources such as solar, wind, geothermal, small-scale hydroelectric, and biomass, but can also include large hydroelectric and nuclear. 2 States with CCAs include California, Illinois, Massachusetts, New Hampshire, New Jersey, New York, Ohio, Rhode Island, and Virginia. States "actively investigating" include Arizona, Colorado, Connecticut, Maryland, and Oregon. Washington is classified as a "Watch List/Potential" state.
} 
Since CCAs give local communities control over electricity procurement decisions, the primary way they reflect local preferences is through electricity resource choice. Most CCAs reflect local preferences for cheaper rates by choosing cheaper electricity resources. Some choose to reflect their community's preference for carbon-free electricity-13\% of CCAs across the U.S. procure voluntary green electricity (O'Shaughnessy et al. 2019a). This means that they buy more power from carbon-free resources than is required by their state's laws.

\section{ii. CCAs in California: direct and indirect effects on renewable energy}

California Assembly Bill (AB) 117 was passed in 2002, enabling CCAs in California (California 2002). The bill, "authorize[s] customers to aggregate their electrical loads as members of their local community with community choice aggregators" (California 2002) and defined CCAs as "any city, county, or city and county [or group of cities, counties, or cities and counties] whose governing board elects to combine the loads of its residents, businesses, and municipal facilities in a communitywide electricity buyers' program...by ordinance," as long as they do not launch within the service territory of an existing publicly owned utility (they can only launch within the territory of an investor owned utility) (California 2002). ${ }^{3}$ In doing so, AB117 allowed for the creation of locally governed electricity providers who make electricity purchasing decisions on behalf of their residents and businesses.

Much like elsewhere in the United States, CCAs in California aim to reflect local preferences. In California, reflecting local preferences has meant that CCAs often focus on providing their communities with environmental benefits, such as carbon-free energy or local energy programs that reduce greenhouse gas emissions. To date, CCAs in California have been a significant tool in advancing California's carbon-free energy goals. Their direct and indirect effects on renewable energy are driving the accelerated progress toward achieving the state's target for $100 \%$ carbon-free energy by 2045 (Trumbull et al. 2019a).
Providing customers with the choice in electricity product is the essence of CCAs. Beyond offering an alternative choice to the local IOU, 21 of California's 23 existing CCAs offer electricity customers multiple electricity products to choose from. This typically includes 1) a "default" electricity product, which is composed of a greater share of renewable energy than offered by the local IOU, and 2) a $100 \%$ renewable energy product. Typically, electricity products with a greater share of renewable energy are more expensive than those with less. By offering customers multiple electricity products, CCAs can capture customers' different levels of willingness to pay for renewable energy.

CCA customers are enrolled automatically into a default electricity product - unless they actively choose another option. Electricity options differ by the type of energy resources used, such as solar or natural gas, as well as the rate charged. The price per kilowatt hour that an electricity customer pays is the default electricity rate. Common CCA customer electricity service enrollment options include: 1 ) 'opt up', when a customer enrolls in a more expensive electricity option or an electricity option with greater amounts of clean energy, 2) 'opt down', when a customer enrolls in a lower-cost electricity option or an electricity option with less amounts of clean energy, 3) 'opt out', when a customer chooses to leave a CCA program, 4) 'opt in', when a customer enrolls back into a CCA program, or 5) 'remain,' when a customer takes no action and remains with the default electricity product. ${ }^{4}$

Some CCAs are shifting from a focus on offering customers an electricity product with a greater share of renewable energy to an electricity product with a greater share of carbon-free energy. Although large hydroelectric generation is not considered renewable, its inclusion can further offset the use of fossil fuel electricity generation, and therefore avoid greenhouse gas emissions and contribute to meeting environmental goals. Existing CCAs offer their customers between one and three different electricity products to choose among (Figure 1). CCAs are not required to offer their customers more

\footnotetext{
${ }^{3}$ There are three main investor-owned utilities in California: Pacific Gas and Electric (PG\&E), Southern California Edison (SCE), and San Diego Gas \& Electric (SDG\&E).

4 These options are available to CCA customers in part due to CCAs offering multiple electricity products to their customers to choose among and in part because of the legislatively required automatic enrollment of CCA customers, the latter of which is discussed further in section $\mathrm{V}$.
} 


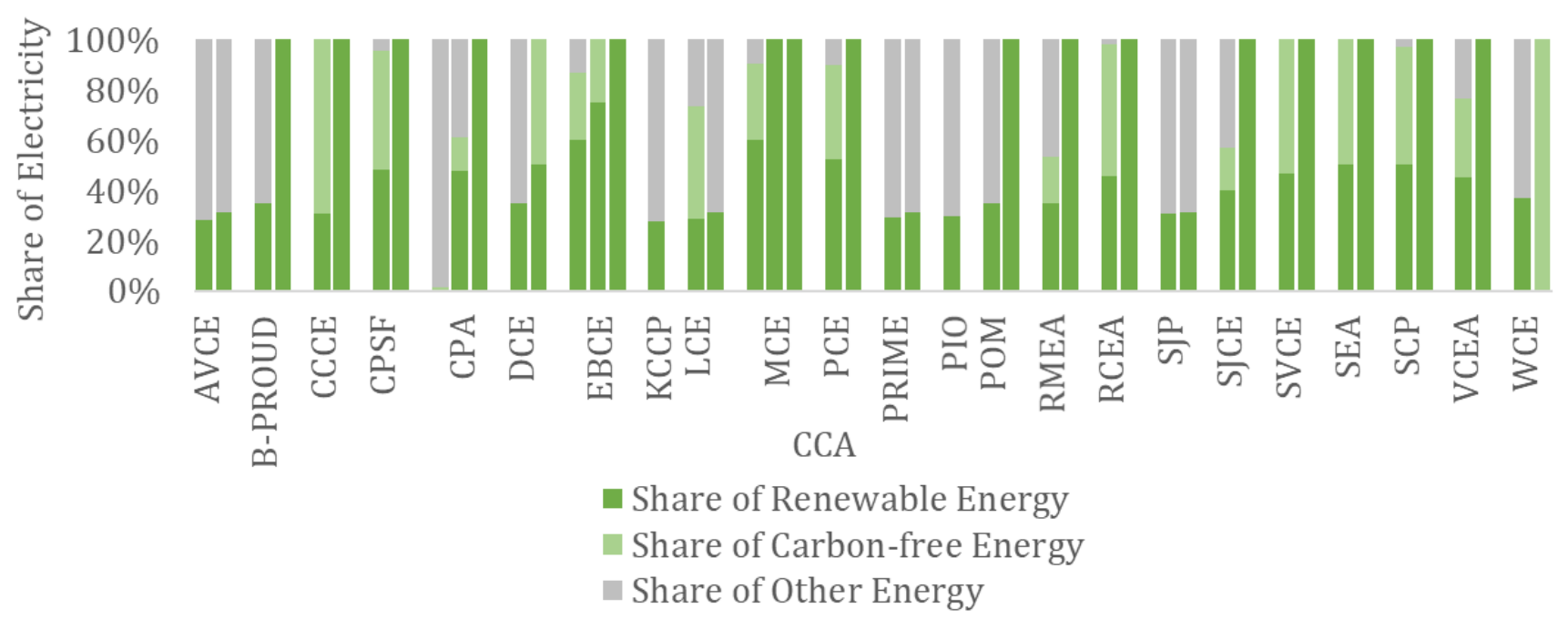

Figure 1: CCA Electricity Products (each of the different electricity products a CCA customer can choose among and its share of different energy sources.) Each bar represents one electricity product. The share of renewable energy in each product is shown in dark green, the share of additional carbon-free energy is shown in light green, and the share of other energy resources is shown in grey. Figure created by UCLA Luskin Center for Innovation. Data from California Energy Commission (2020). "Power Source Disclosure Program."

renewable energy than the affiliate IOU nor are they required to offer multiple electricity products, although many choose to do so.

Increasingly, cities and counties that are members of a CCA are enrolling their customers by default into electricity products with $100 \%$ renewable energy. These $100 \%$ renewable electricity products are typically lower cost than the IOU's $100 \%$ renewable energy option, but more expensive than the IOU's default option. Currently, 14 California cities and counties default enroll customers into a $100 \%$ renewable energy product, and an additional 38 default enroll customers into a 100\% carbon-free energy product. Despite the higher price for the $100 \%$ renewable option, these communities have not seen significantly more customers choosing to switch to a lower-cost product (opt down) or out of the CCA (opt out).

The emergence of CCAs has required incumbent IOUs to be more competitive. An unexpected side effect of CCAs is that their emergence is also contributing to the IOUs' electricity supply becoming increasingly carbon-free in California. Incumbent IOUs have been left with long-term renewable energy contracts that were procured on behalf of customers who have since departed for CCAs. This means they have more renewable energy than is required for fewer customers. This is in part due to California's regulatory environment, the implications of which are described in more detail in Section VI.

CCAs can also support environmental goals by funding local energy programs. CCAs often reinvest their revenues in local energy programs (described further in section V.ii Ensuring sufficient funds to offer local energy programs). For example, most CCAs offer energy efficiency and rooftop solar programs, and multiple CCAs offer electric vehicle rebates and other programs that aim to reduce greenhouse gas emissions and/or customers' electricity bills. In addition to environmental benefits, these programs also often yield other benefits for the customers, community, and the CCA, including increasing bill savings, supporting local jobs, building resiliency, and responding to unique community needs.

\section{CCAs' acceleration of renewable energy consumption}

In this section, we calculate the extent to which CCAs have contributed to exceeding the state's renewable energy targets, both directly and indirectly.

i. Renewables portfolio standard: policy context Arguably the most important piece of legislation related to providing customers with carbon-free energy is the renewables portfolio standard (RPS). California's RPS specifies the percentage of electricity sales required to come from certain 
eligible energy resources and applies to all electricity providers in California, including IOUs, publicly owned utilities, electric service providers, and CCAs. Eligible renewable resources include biomass, geothermal, small hydroelectric, solar, wind, and more (Crume et al. 2017). Large hydroelectric ${ }^{5}$ and nuclear electricity generation are considered clean electricity generation but are not RPS-eligible in California.

California currently has a target of $100 \%$ carbon-free energy by 2045 , as well as interim targets, established by California Senate Bill 100 (2018). Some critics have argued that this requirement for all utilities to procure $100 \%$ carbon-free energy renders CCAs, and their ability to make energy procurement decisions, unnecessary. However, CCAs can support a state's carbon-free energy goals in multiple ways. Beyond offering customer choice, competition, and innovative local energy programs, CCAs make decisions based on community preferences about the type and location of the resources used to meet the $100 \%$ carbon-free energy goal. For example, some communities may prefer locally generated renewable energy rather than out-of-state electricity, or for geothermal generation over solar. More important, CCAs' ability and willingness to procure more carbon-free energy than required helps accelerate achievement of state goals. Critics of CCAs miss a key benefit they provide: By accelerating compliance with carbon-free energy goals; they help states achieve $100 \%$ carbon-free energy sooner and thereby avoid more greenhouse gas and air pollutant emissions. By achieving the RPS more quickly, the state benefits from a cumulatively larger reduction in greenhouse gas emissions each year.

RPS has been key to increasing renewable energy; however, some communities have deemed its "onesize-fits-all" performance standard insufficiently ambitious. CCAs are effective tools in those instances when community demand for renewable energy exceeds the RPS requirements, as they allow communities to choose more renewable energy.

ii. Data and methods to assess CCAs' impact on renewables portfolio standard compliance

Assessing the impact of CCAs on California's renewable energy consumption requires examining two distinct effects. The first effect is the amount of renewable energy that CCAs have delivered in excess of RPS mandates between 2011 and 2019. This direct impact is relatively straightforward. We simply calculate the amount of renewable energy CCAs are required to procure based on their total annual load and state requirements. We then take the actual total annual renewable electricity procured by CCAs and the difference is CCAs' direct effect on RPS over compliance.

The second effect is the amount of renewable energy that IOUs delivered in excess of the RPS goals that can be attributed to the presence of the CCAs. There are two reasons that the emergence of CCAs might have increased the amount of renewable energy delivered by IOUs. First, when a CCA launches within an IOU territory, all of the customers within that geographic area automatically move to the CCA, per the CCAenabling legislation. However, IOUs had signed longterm renewable energy contracts prior to CCA load departure, anticipating that they would need to provide those customers with a RPS-compliant level of renewable energy. Therefore, after a CCA forms, IOUs are left holding more renewable energy contracts than they need for RPS-compliance because they now have a smaller customer base. We attempt to estimate this indirect effect below using a conservative approach.

Due to load departure to CCAs, IOUs have a lower RPS compliance requirement and therefore greater RPS over compliance. Conceptually, our analysis compares IOUs' current RPS-compliant energy requirement with that same requirement under a counterfactual scenario in which CCAs had never formed. To estimate this, we add departed CCA total load back to IOU total load to estimate a counterfactual load and the associated counterfactual RPS compliance requirements if IOUs served all CCA load. Our counterfactual scenario is one in which CCAs had never emerged, meaning IOUs would have had higher renewable energy requirements. We attribute the difference between these two scenarios to the emergence of the CCAs over this period. We acknowledge that this is a shortrun estimate based upon the explicit assumption that IOUs cannot adjust the RPS portfolio holdings in a meaningful way over our period of evaluation (2011 to 2019).

\footnotetext{
${ }^{5}$ Hydroelectric facilities larger than $30 \mathrm{MW}$.
} 
Another reason that CCAs might induce IOUs to increase the amount of renewable energy delivered is to defensively deter the formation of the CCAs within their service territory. IOUs may have increased their renewable energy content ex ante, in part to convince prospective CCAs customers that they did not need to form a CCA in order to consume more renewable energy. The evidence that we will present shows IOUs over complying with the RPS mandates in advance of CCA formation. However, we will not attribute this early over compliance to anticipated CCA formation. We do this because there could be other reasons for this early over compliance beyond CCA formation. The California Public Utilities Commission (CPUC) notes, "A variety of market conditions have caused the IOUs to have procured beyond their minimum RPS requirements. These market conditions include the initial need to hedge against early program experience with project failure, the current climate of increasing departing load to CCAs, and the increase in behind-the-meter solar generation" (California Public Utilities Commission 2018).

Our estimates rely upon the publicly available California Energy Commission (CEC) Power Content Labels (California Energy Commission 2020) for each of the CCAs and the 3 relevant IOUs from 2011 to 2019, when applicable (some CCAs launched after 2011). This data was used as it had the most recent years available and for the most CCAs. The California Energy Commission collects these reports annually from each electricity provider. These reports include annual retail sales (MWh) by each type of electricity generating resource.

To calculate the direct effects of CCAs, we first calculate the amount of renewable energy that CCAs are required to procure each year. We do so by multiplying the annual interim RPS targets to each CCA's annual retail sales for each year. We subtract this value from the sum of all CCAs annual renewable energy procurement each year to calculate direct RPS over compliance. To calculate the indirect effects of CCAs on IOU over compliance, we first sum IOUs' annual RPS targets each year. This total is IOUs RPS requirements in the 'with-CCA' scenario. For our 'without-CCA' analysis, we assume no CCAs would have launched. In this case, all CCA load would have been served by IOUs. We therefore add CCA annual retail sales to the retail sales of the IOU that would have served those customers. We then use the annual percent target to calculate the IOUs' annual RPS targets if they served all CCA load. The difference between IOUs' RPS requirements with- and withoutCCAs represents the indirect effect of CCAs on IOU RPS over compliance.

iii. How much more renewable energy has been consumed because of CCAs?

CCAs' combined direct and indirect contribution has accelerated achievement of state renewable energy goals by 46 million megawatt hours in the past decade (Trumbull et al. 2019a). From 2011 to 2019, CCAs purchased 23.5 million megawatt hours of renewable energy in excess of state requirements, $204 \%$ of what the state required (Trumbull et al. 2019a).

\section{IOU RPS Requirements With and Without CCAs}

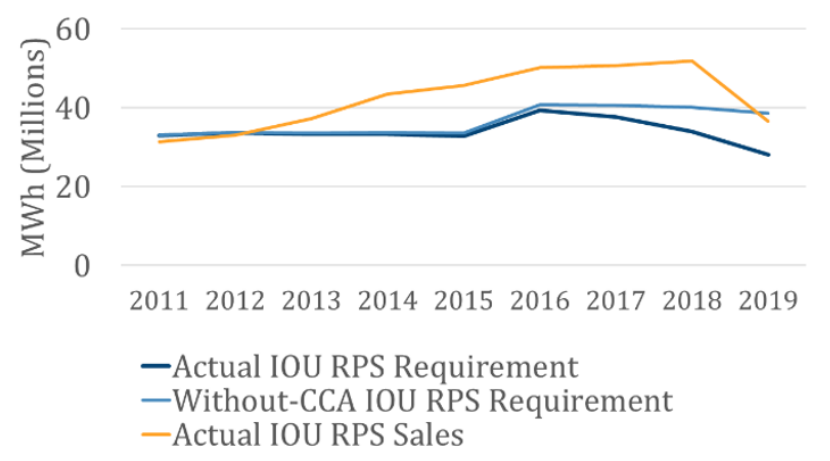

Figure 2: The amount of RPS-eligible energy IOUs' actually purchased is shown in the orange line. The dark blue line shows how much RPS-eligible energy IOUs are actually required to purchase (with-CCA scenario). Given that CCA customers have been departing from IOUs since 2011, IOUs needing less renewable energy to comply with the RPS. The light blue line shows how much RPS-eligible energy IOUs would have been required to purchase in a counterfactual scenario in which CCAs had never emerged.

At the same time, CCAs' indirect effect was IOU over compliance with the RPS of 22.5 million megawatt hours (Trumbull et al. 2019a). Between 2011 to 2019, IOUs procured 74.9 million MWh, or 25\%, more renewable energy than is required by the RPS over that period. However, as we noted above, we cannot attribute all of this IOU over compliance to the emergence of CCAs. Based on our method described above we attribute 22.5 million MWh, or $30 \%$ of their over compliance, to the emergence of CCAs. 
These effects are illustrated in Figure 3, which shows the gigawatt hours (GWh) of renewable energy procured by both IOUs and CCAs since 2011. The solid light blue (IOU) and dark blue (CCA) sections illustrate the required renewable energy procured. The dashed dark blue section represents the amount of renewable electricity CCAs procured in excess of RPS requirements-their direct effect on renewable energy procurement. The dashed light blue section shows the amount of renewable energy procured by IOUs that now exceeds RPS requirements as a result of customer departure for CCAs. This is the indirect effect of CCAs. This analysis includes only renewable energy and does not include CCAs' contributions to carbon-free energy (large hydroelectric generation), which further accelerates achievement of the state's $100 \%$ carbon-free energy target.

Estimated Total Direct and Indirect Effect of CCAs on Renewable Energy Procurement Beyond Requirements

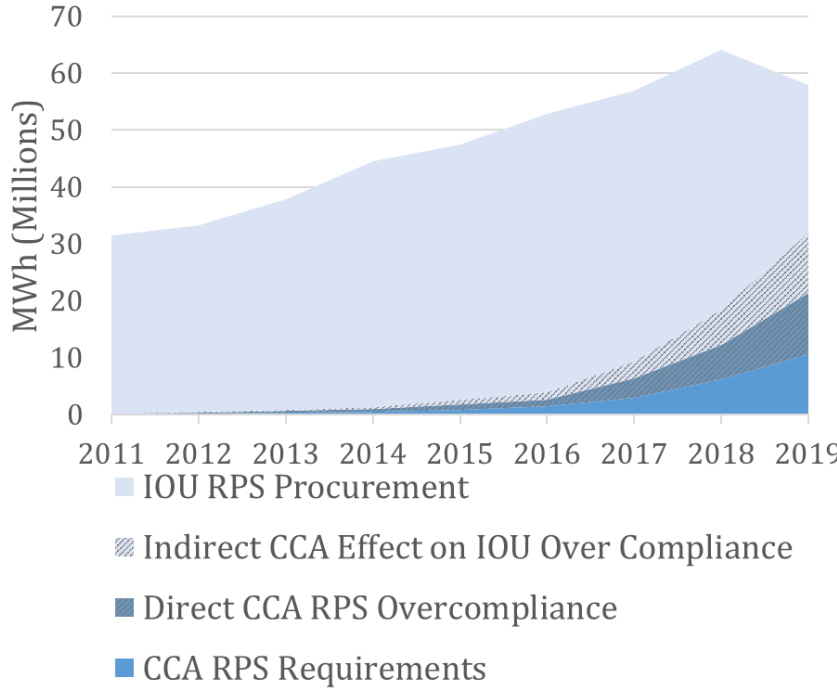

Figure 3: Beyond Requirements. Figure created by UCLA Luskin Center for Innovation. Data from the California Public Utilities Commission (CPUC) 2018 Annual RPS Compliance Reports.

\section{Customer characteristics and local demand for carbon-free energy}

In this and the following sections, we examine the characteristics that have enabled CCAs to be a successful policy tool in accelerating the carbon-free energy transition. We begin with customer characteristics of CCAs and the local demand for carbon-free energy seen in local communities. A wide variety of electricity customers across the U.S. support carbon-free electricity, as evidenced by national public opinion polls (Pew Research Center 2016) and the growing number of $100 \%$ carbon-free energy commitments at the city and county level (Trumbull et al. 2019b). We find that CCAs are most effective at supporting environmental goals in communities where the demand for carbon-free energy exceeds what is currently provided. CCAs can be effective tools to meet these communities' goals as they enable communities to purchase more carbonfree electricity.

In this section, we first examine customer support for carbon-free energy. We then dive deeper into the demographics of the communities served by CCAs in California and how those relate to preferences for carbon-free energy. This section explores the commonalities among communities that have formed CCAs. CCAs successfully serve a wide variety of communities in California. The size and median income of a community are not predictors of success, suggesting that the CCA model can be replicable in a variety of communities across the nation.

\section{i. Local demand for carbon-free energy is found across the U.S.}

We find evidence of a large, unmet demand for carbon-free energy across the United States-that is, communities want more carbon-free energy than they are currently offered. First, public opinion toward carbon-free energy is highly favorable across geographies and political ideology. Pew Research Center found " $83 \%$ of conservative Republicans favor more solar panel farms; so, too, do virtually all liberal Democrats (97\%)" and found similar support for wind (Pew Research Center 2016). Second, local demand for carbon-free energy is outpacing legislative action at the state and federal level. Across 37 states, 204 cities and counties have $100 \%$ carbonfree energy commitments (Trumbull et al. 2019b). Combined, over 110 million people live in regions with a 100\% carbon-free energy commitment (Trumbull et al. 2019b).

CCAs could be one tool for these communities to meet this large carbon-free energy demand, as they are designed to reflect local preferences for carbonfree energy. A 2019 UCLA Luskin Center for Innovation report found that all cities that have achieved $100 \%$ carbon-free energy have control over their electricity supply through their electricity 
provider (Trumbull et al. 2019b). In California, 64 of the 66 communities that are $100 \%$ carbon-free are members of a CCA (Trumbull et al. 2019b). ${ }^{6}$ This report noted that "these local and state-level commitments exist in all regions of the U.S. and many have bipartisan support" (Trumbull et al. 2019b). Empowering communities to have control over decisions concerning their electricity generation sources is proving to be good for the environment.

\section{ii. Demographic analysis of California CCAs}

In this section, we first examine the residential customer characteristics of California CCAs and how these traits have changed over time. We describe how the demographics of communities served by CCAs have diversified as the number of CCAs has grown and, subsequently, the number of member cities and counties. We find that California CCAs represent a variety of communities with different populations, median incomes, and political affiliation. This has become increasingly true as CCAs have expanded across the state over the last decade.

We then look at the relationship between the demographics of CCA member communities and their electricity preferences. We compare CCA member community median income and political affiliation to their chosen default electricity product and default electricity rate. We find that the income and size of member communities are not strongly correlated with the default amount of carbon-free energy chosen by the community. Political affiliation is a stronger indicator of electricity preference. These findings suggest that the CCA model can be successful in a variety of communities with differing sizes and incomes and could therefore be replicable in many places. However, the CCA model may be more effective at supporting environmental goals where local communities support carbon-free energy and have a willingness to pay for it.

\begin{tabular}{|c|c|c|c|c|}
\hline Year & Number of CCAs & $\begin{array}{c}\text { Member Cities } \\
\text { and Counties }\end{array}$ & $\begin{array}{c}\text { Population with } \\
\text { CCA Option }\end{array}$ & $\begin{array}{c}\text { Percent of } \\
\text { Population with a } \\
\text { CCA Option }\end{array}$ \\
\hline 2010 & 1 & 12 & 263,886 & $1 \%$ \\
\hline 2011 & 1 & 12 & 263,886 & $1 \%$ \\
\hline 2012 & 1 & 12 & 263,886 & $1 \%$ \\
\hline 2013 & 1 & 13 & 374,853 & $1 \%$ \\
\hline 2014 & 2 & 22 & 762,501 & $2 \%$ \\
\hline 2015 & 3 & 30 & $1,149,032$ & $3 \%$ \\
\hline 2016 & 5 & 59 & $3,018,448$ & $8 \%$ \\
\hline 2017 & 9 & 82 & $3,983,771$ & $10 \%$ \\
\hline 2018 & 17 & 137 & $7,477,048$ & $19 \%$ \\
\hline 2019 & 19 & 169 & $11,457,003$ & $29 \%$ \\
\hline 2020 & 23 & 182 & $12,233,789$ & $31 \%$ \\
\hline 2021 & $26+$ & $198+$ & $15,743,188+$ & $41 \%$ \\
(Projected) & & & & \\
\hline
\end{tabular}

Table 1: Number of CCAs and population of their member communities over time and projected (U.S. Census Bureau. 2019)

\begin{tabular}{|l|c|c|c|c|c|c|c|c|c|c|}
\hline & $\mathbf{2 0 1 0}$ & $\mathbf{2 0 1 3}$ & $\mathbf{2 0 1 4}$ & $\mathbf{2 0 1 5}$ & $\mathbf{2 0 1 6}$ & $\mathbf{2 0 1 7}$ & $\mathbf{2 0 1 8}$ & $\mathbf{2 0 1 9}$ & $\mathbf{2 0 2 0}$ & $\mathbf{2 0 2 1}$ \\
\hline Min. & 2,135 & 2,135 & 448 & 448 & 448 & 340 & 340 & 340 & 340 & 340 \\
\hline Med. & 11,195 & 12,351 & 10,715 & 13,982 & 25,575 & 27,215 & 30,601 & 34,504 & 36,139 & 36,884 \\
\hline Max. & 69,255 & 110,967 & 178,488 & 178,488 & 883,963 & 883,963 & 883,963 & $1,057,162$ & $1,057,162$ & $1,419,845$ \\
\hline
\end{tabular}

Table 2: Range in population of CCA member communities over time (U.S. Census Bureau. 2019)

\footnotetext{
${ }^{6}$ The other two cities with $100 \%$ clean energy procure their electricity from publicly owned utilities, a type of electricity provider in which the electricity generation, transmission, and generation are all owned and operated publicly, often municipally.
} 


\begin{tabular}{|l|c|c|c|c|c|c|c|c|c|c|}
\hline & $\mathbf{2 0 1 0}$ & $\mathbf{2 0 1 3}$ & $\mathbf{2 0 1 4}$ & $\mathbf{2 0 1 5}$ & $\mathbf{2 0 1 6}$ & $\mathbf{2 0 1 7}$ & $\mathbf{2 0 1 8}$ & $\mathbf{2 0 1 9}$ & $\mathbf{2 0 2 0}$ & $\mathbf{2 0 2 1}$ \\
\hline Min. & $\$ 75,668$ & $\$ 54,857$ & $\$ 30,000$ & $\$ 30,000$ & $\$ 30,000$ & $\$ 30,000$ & $\$ 30,000$ & $\$ 30,000$ & $\$ 30,000$ & $\$ 30,000$ \\
\hline Med. & $\$ 106,192$ & $\$ 100,681$ & $\$ 79,026$ & $\$ 76,139$ & $\$ 81,955$ & $\$ 81,431$ & $\$ 74,748$ & $\$ 76,609$ & $\$ 74,512$ & $\$ 71,554$ \\
\hline Max. & $\$ 186,477$ & $\$ 186,477$ & $\$ 186,477$ & $\$ 186,477$ & $\$ 250,001$ & $\$ 250,001$ & $\$ 250,001$ & $\$ 250,001$ & $\$ 250,001$ & $\$ 250,001$ \\
\hline
\end{tabular}

Table 3: Range in income of CCA member communities over time (U.S. Census Bureau 2014).

\section{Population}

The 23 operational CCAs in California currently serve 165 member cities and 17 member counties, for a total of 182 member communities. CCAs range in size from one to 34 member communities. Commonly, a city or county joins a CCA when it launches; however, 34 jurisdictions joined an existing CCA after it began operation. An additional 16 communities are expected to form new CCAs in 2021.

In 2020, almost a third of the state's population has choice in their electricity provider. This has grown from $1 \%$ of the population in 2010 and is expected to grow to $41 \%$ in 2021, with multiple CCAs expected to launch in the San Diego area and elsewhere across the state. Table 1 summarizes how the number of CCAs and the total population of their member communities has increased over time.

CCA member communities vary in size, and the diversity in their size has increased over time. In 2020 , the smallest community served by a CCA is Trinidad, a member of Redwood Coast Energy Authority, with a population of 340 . The largest community is Unincorporated Los Angeles County, a Clean Power Alliance member, with a population of more than 1 million. The median size of a member community has increased over time; in 2020 the median population of a CCA member community is more than 36,000 . Table 2 shows how the range in median population of member communities has grown over time.

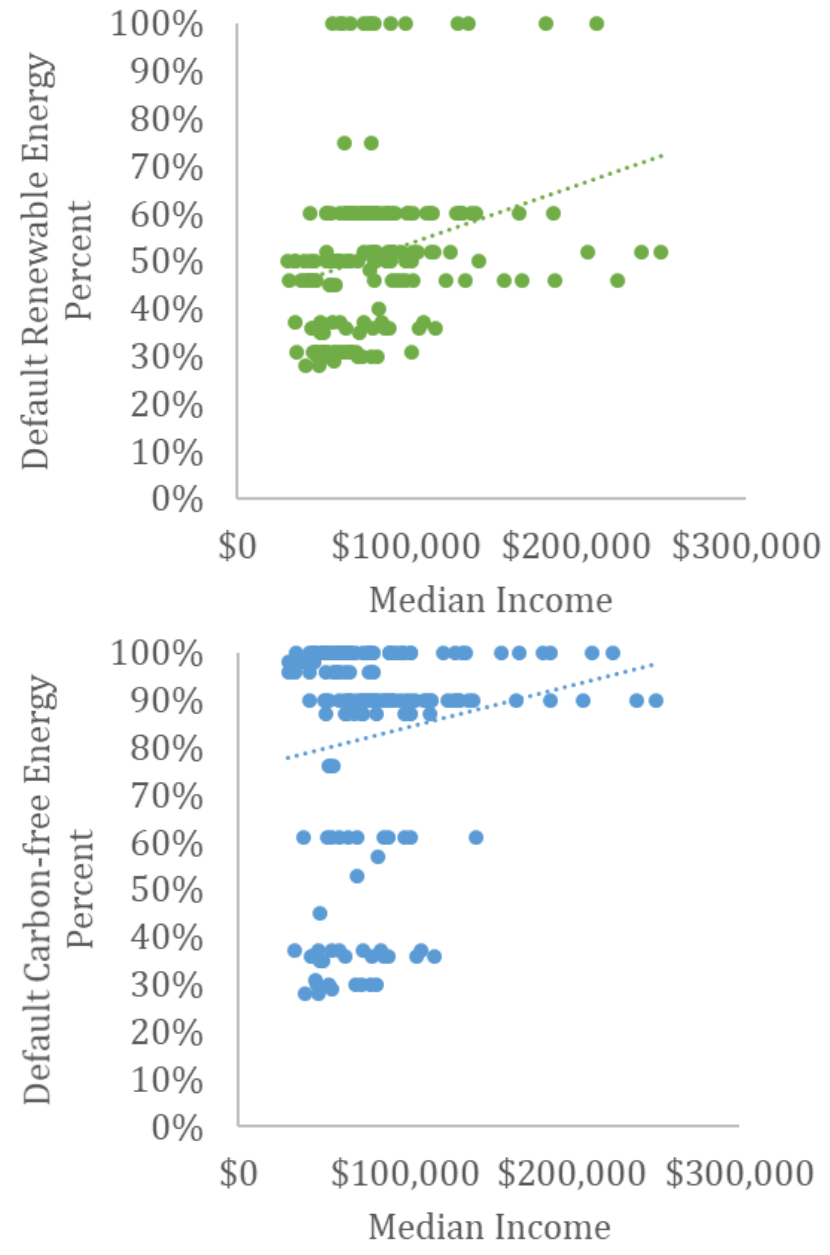

Figure 4: Member community median income and default electricity product share of renewables (top) and carbonfree resources (bottom). These figures show the relationship between the median income of CCA member communities and the share of renewable (green points) and carbon-free (blue points) energy resources in their default electricity product. Each point represents a CCA member community. 


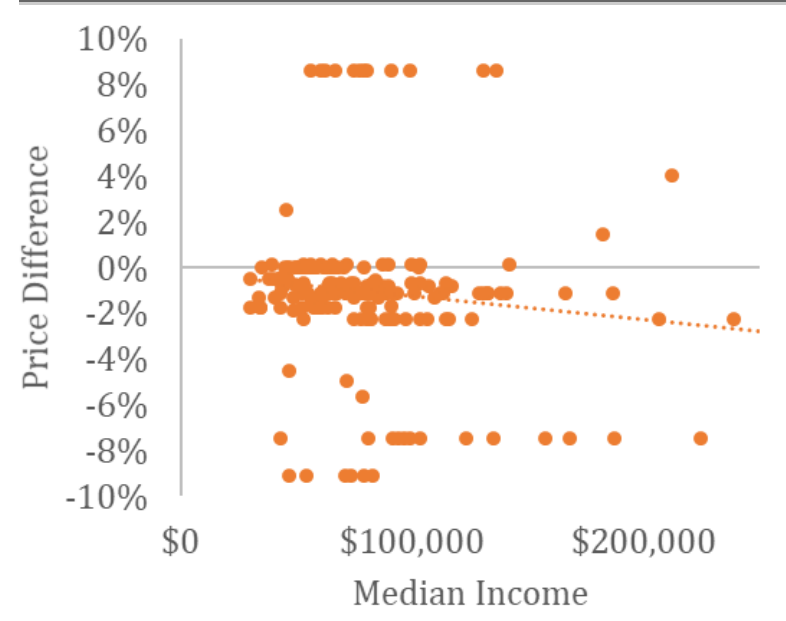

Figure 5: Member Community Median Income and Rate Price Difference (\%) Compared to Affiliate IOU. This figure shows the relationship between a CCA member community's median income and the price difference compared to its affiliate IOU; i.e., the alternative electricity provider a CCA's customers can choose. Figure created by UCLA Luskin Center for Innovation. Median income data from U.S. Census Bureau. Rate data from each Joint Rate Comparison for each CCA and their affiliate IOU. All rates are accurate as of time of analysis in April 2020.

\section{Income}

Diversity in the median household income of CCA member communities has also increased over time. Only one CCA existed in 2010, with a median income of $\$ 106,192$. In 2020 , the median income was $\$ 74,512$ and ranged from $\$ 30,000$ to $\$ 250,001$. The extent of incomes among member communities has also increased greatly. Table 3 shows how the median income and range in median income of member communities has changed over time.

CCA member communities support renewable and carbon-free energy across median income levels. The 14 member communities that enroll by default into the $100 \%$ renewable energy product have a range of median incomes from $\$ 56,025$ (West Hollywood, a member of Clean Power Alliance) to $\$ 212,222$ (Piedmont, a member of East Bay Community Energy). We found that there is a trend, as higherincome communities tend to choose default electricity products with greater amounts of renewable energy; for every $\$ 10,000$ increase in the median income of a community, the default electricity product has 1.2 percentage points more renewable energy, on average $(\mathrm{p}<0.05)$.

An even greater variety of communities support $100 \%$ carbon-free energy (renewable energy plus hydroelectricity). The median income range for the 54 communities with a $100 \%$ carbon-free energy default product is from $\$ 34,659$ to $\$ 224,271$. More than two-thirds of existing CCA member communities - 128 cities and counties representing a population of 6.2 million - have a default product with over $90 \%$ carbon-free energy in their default product. These communities' median incomes range from $\$ 30,000$ to $\$ 250,001$. Higher-income communities also tend to choose default electricity products with greater amounts of carbon-free energy; for every $\$ 10,000$ increase in the median income of a community, the default electricity product has 0.9 percentage points more carbon-free energy, on average $(\mathrm{p}<0.05)$ (Figure 4).

We find a slight trend between the median income of a community and the electricity rate: the electricity rate becomes cheaper as the median income of a member community increases (Figure 5). However, this is not statistically significant.

\section{Political affiliation}

Diversity in political affiliation among CCA member communities has also increased over time. The range has become wider, and the median has moved closer to actual shares of registered voters in the state. In 2020, CCA member communities have between $18 \%$ and $69 \%$ registered Democrats, with a median of $48 \%$, and between $3 \%$ and $56 \%$ registered Republicans, with a median of $20 \%$. For comparison, in 2020, $45.3 \%$ of all voters in California registered as Democrats and 23.9\% registered as Republicans (California Secretary of State 2020).

Political affiliation is a stronger predictor of default carbon-free and renewable energy share, as well as default rate, than income. Communities with a greater share of registered Democrats tended toward having a default product with higher amounts of renewable and carbon-free energy (Figure 6), while the opposite was true for communities with a greater share of registered Republican voters (Figure 7). However, Republican communities with larger shares of registered Republicans still had default products with large shares of renewable and carbon-free energy.

For every 10-percentage-point increase in the share of registered Democrats, the default share of renewable energy increases by 4.9 percentage points and the default share of carbon-free energy increases 
by 10.6 percentage points when controlling for median income, on average. For every 10-point increase in the share of registered Republicans, the default share of renewable energy decreases by 4.2 percentage points and the default share of carbonfree energy decreases by 10.6 percentage points when controlling for median income, on average.

\begin{tabular}{|l|r|r|r|r|r|r|r|r|r|r|}
\hline & $\mathbf{2 0 1 0}$ & $\mathbf{2 0 1 3}$ & $\mathbf{2 0 1 4}$ & $\mathbf{2 0 1 5}$ & $\mathbf{2 0 1 6}$ & $\mathbf{2 0 1 7}$ & $\mathbf{2 0 1 8}$ & $\mathbf{2 0 1 9}$ & $\mathbf{2 0 2 0}$ & $\mathbf{2 0 2 1}$ \\
\hline \multicolumn{8}{|c|}{ Democrat } \\
\hline min & $43 \%$ & $43 \%$ & $43 \%$ & $39 \%$ & $35 \%$ & $27 \%$ & $22 \%$ & $22 \%$ & $18 \%$ & $18 \%$ \\
\hline median & $57 \%$ & $57 \%$ & $55 \%$ & $54 \%$ & $52 \%$ & $50 \%$ & $49 \%$ & $49 \%$ & $48 \%$ & $47 \%$ \\
\hline max & $67 \%$ & $67 \%$ & $67 \%$ & $67 \%$ & $67 \%$ & $67 \%$ & $69 \%$ & $69 \%$ & $69 \%$ & $69 \%$ \\
\hline \multicolumn{8}{|c|}{ Republican } \\
\hline min & $6 \%$ & $6 \%$ & $6 \%$ & $6 \%$ & $6 \%$ & $6 \%$ & $3 \%$ & $3 \%$ & $3 \%$ & $3 \%$ \\
\hline median & $14 \%$ & $13 \%$ & $15 \%$ & $16 \%$ & $16 \%$ & $17 \%$ & $18 \%$ & $18 \%$ & $19 \%$ & $20 \%$ \\
\hline max & $26 \%$ & $26 \%$ & $26 \%$ & $29 \%$ & $30 \%$ & $42 \%$ & $48 \%$ & $48 \%$ & $56 \%$ & $56 \%$ \\
\hline
\end{tabular}

Table 4: Range in Political Affiliation of CCA Member Communities over Time summarizing how the range and median share of registered Democrats and Republicans has changed as the number of new CCA member communities has grown over time. Voter registration data from California Secretary of State 2020.
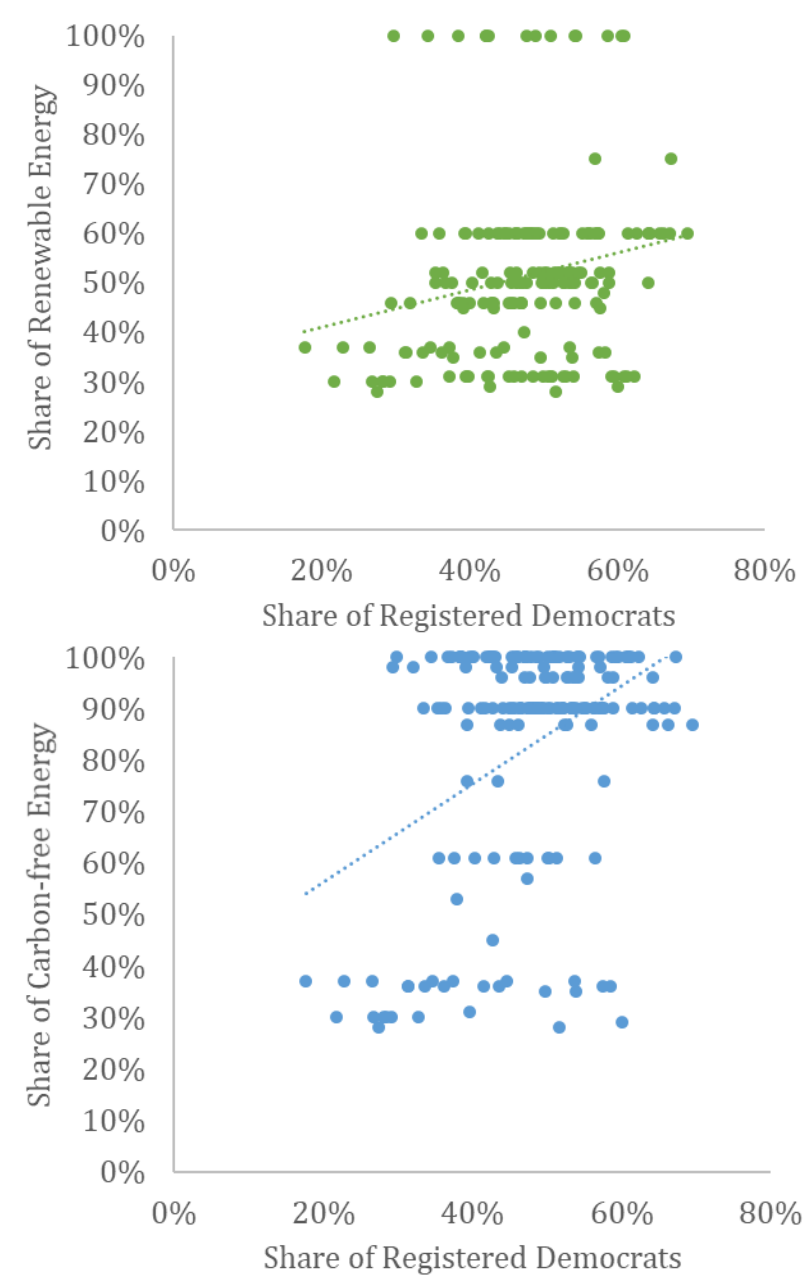

Figure 6: Share of registered Democrat voters to default renewable (top) and carbon-free energy share (bottom)

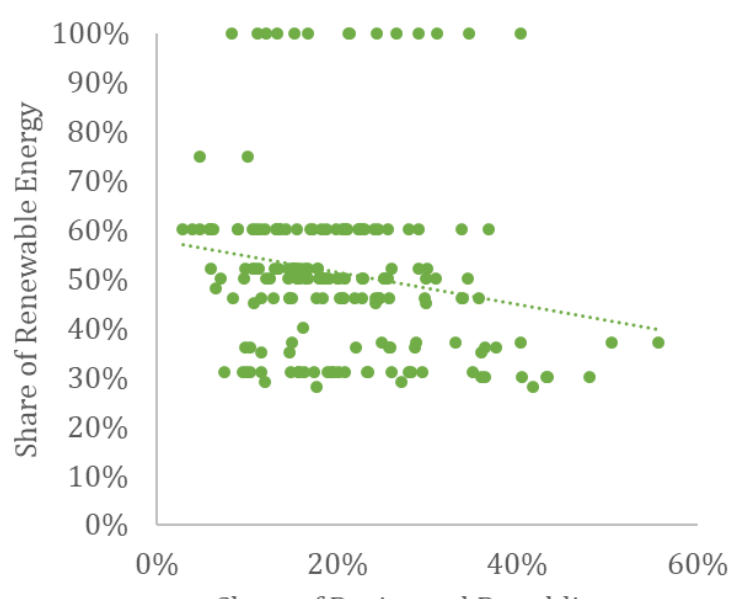

Share of Registered Republicans

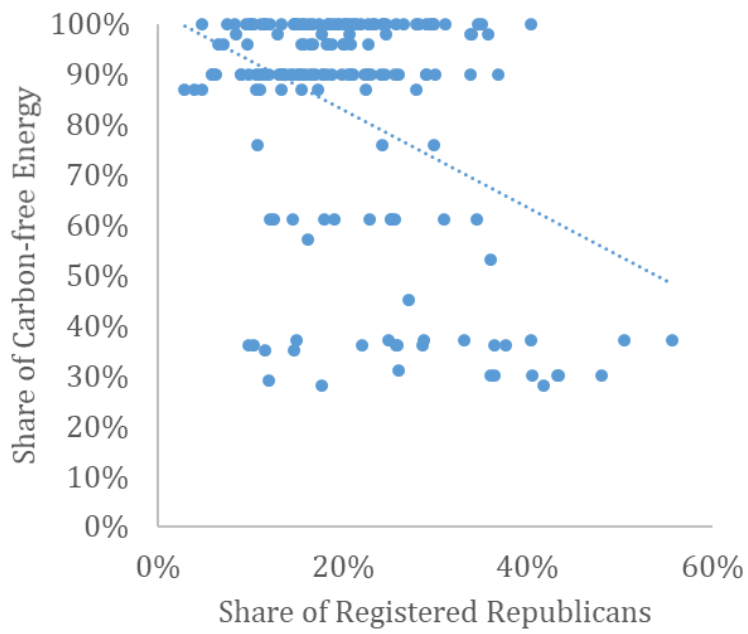

Figure 7: Member communities' share of registered Republican voters and their default renewable (top) and carbon-free (bottom) energy share 
Next, we compare the political affiliation of CCA member communities to the price difference relative to their affiliate IOU. We find a slight relationship between political affiliation and default electricity rate (Figure 8). Communities with higher shares of Republican voters tend to offer default electricity products with lower-cost rates compared to the affiliate IOU, while the opposite is true for communities with higher shares of Democratic voters. ${ }^{7}$ This does not necessarily mean that communities with higher shares of Republican voters are always cheaper or that communities with higher shares of Democratic voters are more expensive than their affiliate IOU. Rather, generally, the more Republican a community is, the larger its rate discount relative to the IOU, and the more Democrat, the smaller the rate discount.

While we found a trend between greater shares of registered Republican voters and less renewable and carbon-free energy, it is possible that this is simply reflecting these communities' preference for lowercost rates. These findings do not necessarily mean that more conservative communities do not support renewable energy, but rather that cost savings is more important. Two recent Yale studies found that there is bipartisan support for renewable energy (Leiserowitz et al. 2018); however, registered Republicans had less of a willingness to pay more for renewable energy (Gustafson et al. 2019). This does not mean that a preference for lower-cost energy is prohibitive to supporting carbon-free energy. Yale researchers note, "Public willingness to pay more for renewable energy is likely to become less relevant in coming years, because the costs of generating electricity from renewable energy sources have been rapidly declining" (Gustafson et al. 2019).

\section{CCA design features that support environmental goals}

As electricity providers, CCAs support environmental goals in two ways. The first and most significant is by choosing electricity generation sources and purchasing carbon-free energy. Second, depending on their financial ability, CCAs invest in local energy programs, such as energy efficiency or electric vehicle rebate programs, that often result in additional greenhouse gas reductions. Offering these programs

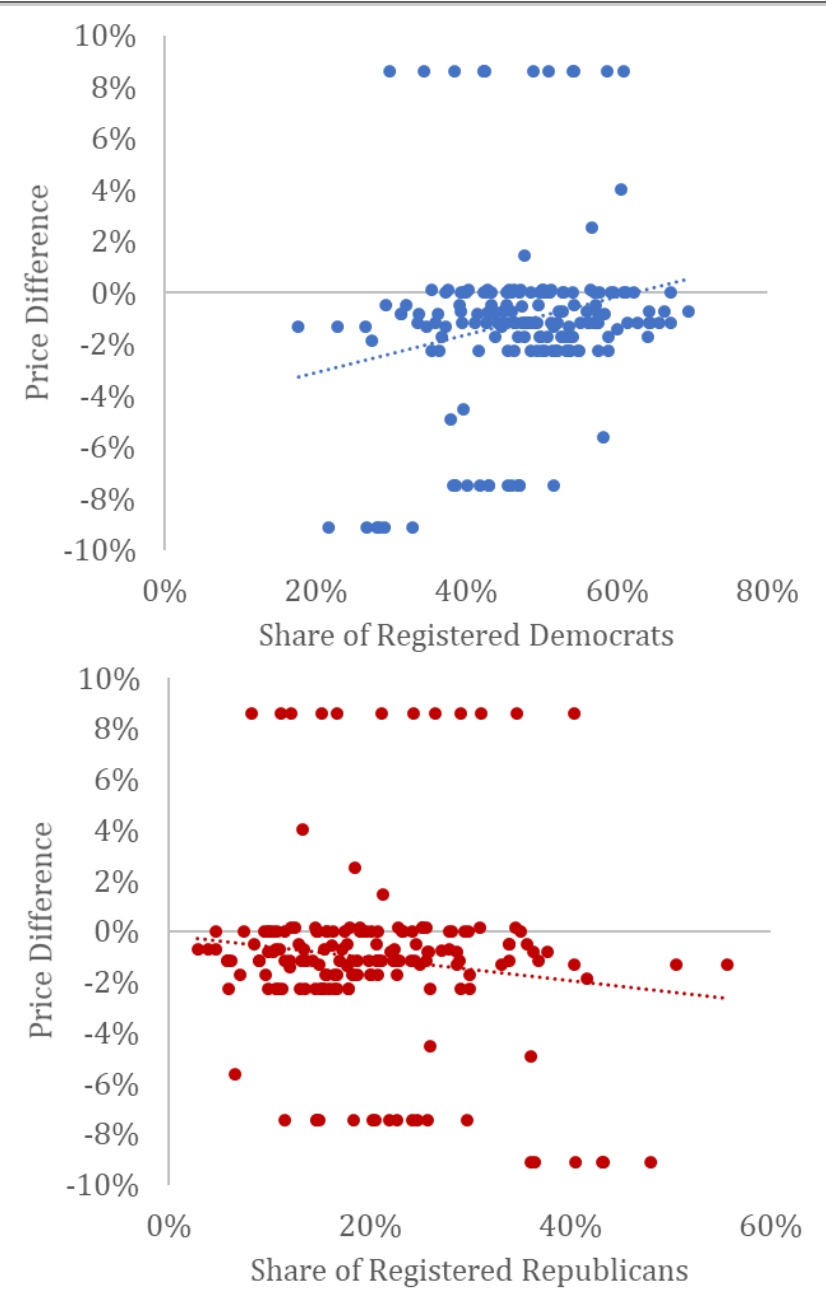

Figure 8: Default rate compared to affiliate IOU by political affiliation. Figure created by UCLA Luskin Center for Innovation. Voter registration data from California Secretary of State. Rate data from each Joint Rate Comparison for each CCA and their affiliate IOU. All rates are accurate as of time of analysis in April 2020.

is not required, but many California CCAs choose to reinvest revenues to bring additional financial and environmental benefits to the communities they serve.

To support these environmental goals, CCAs must first be financially solvent. To do so, a CCA must gain a sufficient customer base and then retain those customers by staying competitive with their affiliate IOU. In this section, we examine the design features of CCAs that enable them to succeed in these ways.

\footnotetext{
7 This relationship between price difference and political affiliation is statistically significant for the share of registered Democrat voters but not for registered Republican voters.
} 
We first focus on two designs of California CCAs that support their ability to ensure a sufficient customer base: 1) within single jurisdictions by legislative design and 2) among multiple jurisdictions joined as a result of a practical business decision. Per the state's CCA-enabling legislation, customers are automatically enrolled in a CCA but can voluntarily opt out. In this section, we discuss why this automatic enrollment is essential to gaining sufficient customers within a jurisdiction. These jurisdictions can join together to increase their customer bases, which can increase the economies of scale benefits, as we will present here. Both design features support gaining customers, which in turn supports CCAs' financial health, enabling them to provide environmental benefits.

CCAs must also maintain this customer base by remaining competitive with the affiliate IOU. CCAs can do this by providing additional value to customers by offering a combination of: 1) lower-cost electricity, 2) cleaner energy, and 3) more attractive local energy programs. The primary design feature that supports CCAs' ability to offer this additional value is their rate-setting authority. That is, CCAs can set the electricity rate for their customers. In this section, we compare CCA rates to those of their affiliate IOU. We find that, although most rates are set just below those of the IOU, some communities are willing to pay higher rates for even greater amounts of carbon-free energy. We discuss how rate-setting authority, as well as external market factors, have helped CCAs keep costs low. Furthermore, CCAs can choose to set a rate so that they can reinvest net revenues into local energy programs. These local energy programs not only provide benefits for CCA customers but can also provide financial benefits to the administering CCA. By remaining a more attractive option than the IOU, CCAs can continue to remain financially solvent and therefore continue to provide environmental benefits.

\section{i. Ensuring a robust customer base}

Ensuring a robust customer base is the foundation for the financial stability that facilitates a CCA's successful provision of environmental benefits. In this section, we examine two CCA design features that enable them to gain customers: 1) automatic enrollment with voluntary opt-out and 2) collaboration with other cities and counties and other CCAs.

Automatic enrollment with voluntary opt out: maximizing customer aggregation

A common trait across CCAs is their "opt out" feature. Stipulated in the enabling legislation (California 2002), ${ }^{8}$ it means that all customers within the city or county's geographical territory are automatically enrolled in a CCA when it launches. While sometimes controversial, this mechanism is critical for CCA success, as it enables CCAs to gain and maintain a critical mass of customers necessary for successful operation (O'Shaughnessy et al. 2019a). In California, CCA's opt-out rates have remained low, with retention averaging above 95\% (O'Shaughnessy et al. 2019a).

As identified in the previous section, the local demand for greener electricity is the foremost condition for CCAs to be successful in supporting the state's carbon-free energy goals. However, the active effort required to switch to a cleaner electricity product or provider may pose a barrier to customers. Automatic enrollment removes this barrier and makes it easy for customers with a desire for cleaner energy to have access to it, without needing to make any effort.

\section{Multi-member and collaborative CCAs: increasing economies of scale}

Multi-member CCAs are common in California. ${ }^{9}$ Of the 23 operational CCAs in California, 11 have more than one member city or county; 170 of the 182 CCA communities are a part of a multi-member CCA. This is somewhat unique to California CCAs. Only a few of the 750 CCAs in other states have more than one member (O'Shaughnessy et al. 2019a). One of the many reasons for a community to join forces in exchange for giving up partial decision-making authority is the economies of scale advantage; that is,

\footnotetext{
${ }^{8}$ California Assembly Bill 117 (2002). "Under community choice aggregation, customer participation may not require a positive written declaration, but all customers shall be informed of their right to opt out of the community choice aggregation program. If no negative declaration is made by a customer, that customer shall be served through the community choice aggregation program."

9 These multimember CCAs are known as "Joint Powers Authorities." This is a legal structure in which "assets and liabilities of the CCA program remain separate from those of the county or city general funds." (DeShazo et al. 2017).
} 
a larger CCA can benefit from lower costs. By including more member communities, CCAs can increase their electricity sales (a measure of their size). There is evidence that the larger the CCA, the lower the costs per electricity sale. Keeping costs low further supports maintaining customers, as discussed in section III.ii, Remaining competitive by keeping costs low to offer carbon-free energy and local programs.

Using publicly available CCA financial statements, we conducted an economies of scale analysis. We first look at economies of scale in non-energy operating costs. Electricity sale revenues primarily cover energy procurement costs. Non-energy operating costs are more minimal and do not proportionally increase or decrease with the number of customers. These non-energy operating costs consist mostly of general and administrative expenses, personnel, and other overhead expenses. ${ }^{10}$ We find that for every increase in a CCA's size by 1,000 gigawatt hours (GWh) in electricity sales (Figure 9), a CCA's nonenergy operating costs per GWh decrease by $\$ 451$ on average when controlling for the year a CCA launched.11

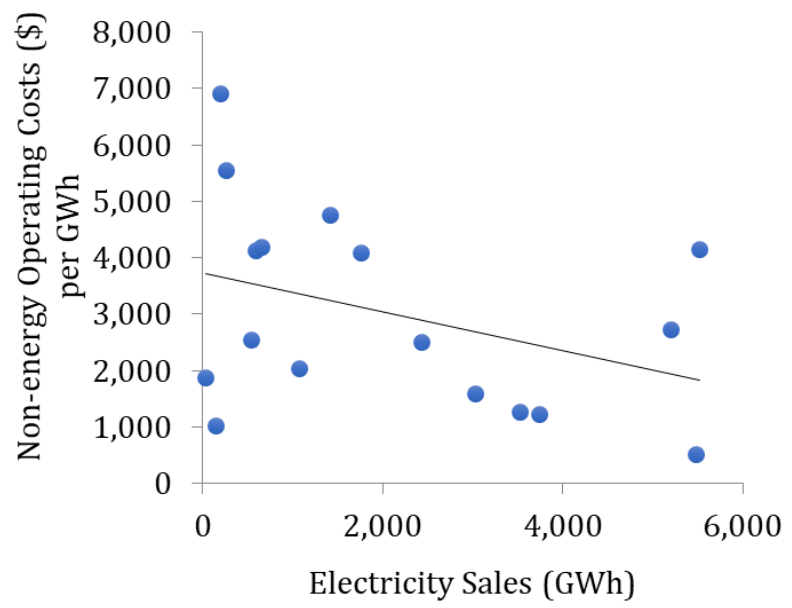

Figure 9: CCA Non-energy Operating Costs (\$) per GWh by CCA Size (Electricity Sales) illustrating the relationship between CCA size in terms of electricity sales and nonenergy operating costs per GWh of electricity sales.
We next examine evidence of economies of scale in energy costs, which make up the majority of a CCA's expenses. These costs generally scale as a CCA grows. Furthermore, energy costs are also influenced by the amount, type, length, and date of the contracts signed with renewable energy generation facilities for electricity. However, we do see evidence of economies of scale in CCA energy costs. While not statistically significant, for every increase in a CCA's size by 1,000 GWh in electricity sales, a CCA's energy costs per GWh decrease by $\$ 2,839$ on average, when controlling for the year a CCA launched. ${ }^{12}$ This means that the greater a CCA's electricity sales, the lower its per-unit energy costs (Figure 10).

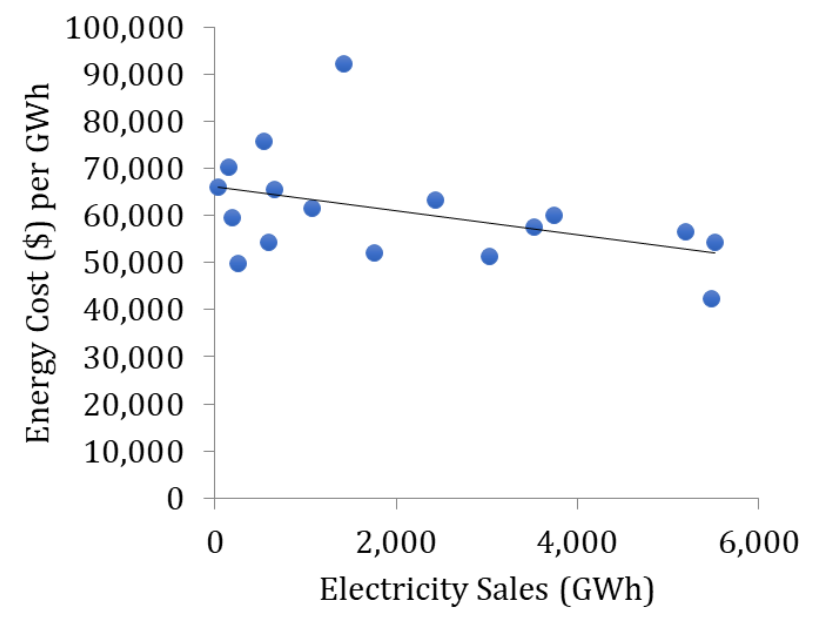

Figure 10: CCA Energy Costs (\$) per GWh by CCA Size (Electricity Sales)

In addition to cities and counties collaborating to form CCAs, California is also seeing cross-CCA collaboration to achieve economies of scale in power procurement costs. Recently, two multimember northern California CCAs, Silicon Valley Clean Energy and Central Coast Community Energy, signed two joint power purchasing agreements. The two contracts represent a combined 210 megawatts of electricity from geothermal resources and solar plus battery storage (Silicon Valley Clean Energy 2020a).

Another way CCAs collaborate with each other is through CalCCA, California's CCA trade association. Twenty five of the 26 existing and soon-to-launch CCAs are members of this association, which provides

\footnotetext{
10 Other non-energy operating costs typically include professional services, legal, regulatory efforts, marketing and promotions, customer service, and other utility or California Independent System Operator (CAISO) fees.

11 Statistically significant at an alpha value of 0.05 .

12 Statistically significant at an alpha value of 0.1 .
} 
"education, technical guidance, and regulatory and legislative advocacy" (CalCCA 2020a).

ii Remaining competitive by keeping costs low to offer carbon-free energy and local programs

In this section, we examine how CCAs can use their rate-setting authority to provide additional value to customers, which can support retaining those customers. CCAs can provide additional value by offering customers 1) lower-cost electricity, 2) cleaner energy, and 3) more attractive local energy programs. CCAs can aim to set rates low enough to provide cleaner energy at lower rates, but high enough to have sufficient revenues for local energy programs, such as rooftop solar or battery energy storage incentives.

Rate-setting authority: the ability to flexibly offer competitive products to customers

Despite being partially regulated by the California Public Utilities Commission (CPUC), CCAs are principally governed by their boards of directors composed of elected officials. This board has ratesetting authority. Consequently, they can set the rates for electricity as they choose and implement innovative programs without the CPUC's approval, unlike IOUs. This provides CCAs with the ability to remain competitive in order to retain customers.

As described in the introduction to this section, CCAs and IOUs are responsible for setting different components of a customers' bill (Table 5). CCAs are responsible for energy procurement, while IOUs continue to provide transmission and delivery services. This means CCAs have control only over setting the generation rate component of a customer's bill, which covers costs associated with energy procurement for electricity generation. The other components of a customer's bill (transmission and delivery, and other fees) are set by the IOU with approval from the CPUC. The sum of these components forms a customer's total electricity bill, which is charged per unit of electricity. By having control over the generation rate, CCAs can choose if and how much of a discount to offer compared to the incumbent IOU.

\begin{tabular}{|l|l|l|}
\hline $\begin{array}{c}\text { Customer Bill } \\
\text { Component }\end{array}$ & $\begin{array}{c}\text { CCA } \\
\text { Customer }\end{array}$ & $\begin{array}{c}\text { IOU } \\
\text { Customer }\end{array}$ \\
\hline Generation rate & CCA & IOU* $^{*}$ \\
\hline $\begin{array}{l}\text { Delivery and } \\
\text { transmission rate }\end{array}$ & IOU* & IOU* $^{*}$ \\
\hline Fees** & CPUC & N/A \\
\hline
\end{tabular}

Table 5: Entity Responsible for Setting Each Bill Component for CCA and IOU Customers

* With CPUC approval

** Fees include the power charge indifference adjustment (PCIA), which is an exit fee charged to CCA customers, and are set based on a CPUC methodology. This is described more in section VI.i Renewables portfolio standard: longterm contracts and their implications for competition.

CCAs have some constraints on the extent of the discount they choose to offer. First, they need to set the rate sufficiently high to recover energy and nonenergy operating costs. The energy resources a CCA chooses to procure can therefore affect how low they are able to set the rates. For example, the International Renewable Energy Agency found that in 2019, large photovoltaic solar generation cost 6.8 cents per kilowatt hour, while onshore wind generation cost 5.3 cents per kilowatt hour (IRENA 2020). Second, CCA customers are charged fees, including an "exit fee." This means that in order to provide a discount compared to the IOU's total electricity rate, a CCA's generation rate plus fees must be lower than the IOU's generation rate. These fees are described more in VI.i Renewables Portfolio Standard: Long-Term Contracts and Their Implications for Competition. Third, CCAs need to set the generation rate sufficiently high to develop reserves or to fund local energy programs. This is discussed more under section V.ii. Ensuring sufficient funds to offer local energy programs.

CCAs can be innovative because they have the authority to set rates. For example, the CCA in Los Angeles and Ventura counties, Clean Power Alliance, chooses to offer low-income customers 100\% renewable energy at the same price at which they were previously paying for electricity with lower amounts of renewable energy through the incumbent IOU (including with their low-income customer discount). Low-income customers in California have access to a number of rate assistance programs that offer discounts on electricity bills, and those 
customers retain those discounts when they join CCAs (Clean Power Exchange 2020).

Another example of innovative rate setting was seen at Central Coast Community Energy, a CCA on the central coast. For its first few years of operation, it matched its rates to the IOU. Customers could choose between receiving a biannual rebate or reinvesting their rebate in supporting the development of local renewable energy or local energy programs (Monterey Bay Community Power 2018). This means that customers saw customers seeing no change in their monthly electricity bill rate; however, they could choose to receive a lump-sum discount or to invest in supporting additional environmental efforts. Similarly, MCE, formerly known as Marin Clean Energy and the oldest California CCA, offers a "Local Sol" rate, which allows customers to directly support the development of solar projects in the community. This rate is locked in for the length of the solar contract, so customers are protected from future rate increases (MCE 2020a). Another example of innovative use of rate setting authority can be found in Silicon Valley Clean Energy, which serves 13 communities in Santa Clara County. They plan to develop a commercial and industrial Clean Power Offerings program in which large commercial and industrial customers could have an additional electricity product option that balances their desire for specific types of cleaner energy and cheaper rates (Silicon Valley Clean Energy 2019).

CCAs' ability to provide lower-cost rates than their competing electricity provider is an important source of additional value for many customers and supports ratepayers' willingness to remain with the CCA. In California, CCAs have historically remained both cheaper and cleaner than their IOU competitors, with few exceptions. However, this does not necessarily mean that a CCA must always be the cheaper option. Increasingly, CCA member communities are opting for a more expensive default product with an even greater share of renewable energy. The resulting effect on residential customers' electricity bills is not substantial. For example, the East Bay Community Energy CCA's 100\% renewable product was only about \$2 more per month for their average residential customer compared to their affiliate IOU's default electricity product that only had less renewable energy (Pacific Gas and Electric and East Bay Community Energy 2020). The Clean Power Alliance CCA's $100 \%$ renewable product was about $\$ 9$ more per month for their average residential customer compared to their affiliate IOU's default electricity product, also with less renewable energy (Southern California Edison and Clean Power Alliance 2020). ${ }^{13}$ Still, these communities highlight that the additional value cleaner energy brings to customers can sometimes be greater than cheaper rates.

As noted in section II., California CCAs are not required to offer greater amounts of renewable energy than their affiliate IOU or more than one electricity product. For example, King City Community Energy, a single-city CCA in Monterey County, and Pioneer Community Energy, a CCA serving multiple communities in Placer County, each offer only one electricity product. While they provide less renewable energy than their affiliate IOU, these products offer bill savings of $1 \%$ and $9 \%$ to their customers, respectively (Pacific Gas \& Electric and Pioneer Community Energy 2020) (Pacific Gas \& Electric and King City Community Power 2020). Although these CCAs may be reflecting their communities' preference for electricity bill savings, the risk to this strategy is that they are competing with the affiliate IOU exclusively on price. With no additional value to the electricity product beyond price, these CCAs may face higher numbers of customers opting out if their rates become comparatively more expensive. Products with greater amounts of renewable energy may have additional marketing value for customers who are willing to pay for a cleaner product.

Through our analysis, we compare the rate of CCA member communities' default electricity product to the rate of their affiliated IOU's default electricity product. The default electricity rate is the total price per kilowatt hour that an electricity customer pays unless they actively choose to enroll in another option. The majority of CCA member communities choose to offer a default rate that is lower cost than their affiliate IOU's default rate, as of publication of this report (Figure 11). Of 182 CCA member communities, 131 , or $73 \%$, choose to offer a lower rate. This discount ranges from $0.004 \%$ to $9.1 \%$. About $13 \%$ of CCA member communities have a

13 These example price differences are correct as of May 2020 for East Bay Community Energy and April 2020 for Clean Power Alliance. Price differences depend on how much electricity the customer consumes, among other factors. 
default rate that is the same as the affiliate IOU (24 out of 182).

While we find that most CCA rates are set just below the rates of the IOU, some communities are willing to pay higher prices for even greater amounts of clean energy. Eleven communities have a default rate that is only slightly higher $(0.1 \%)$ than their affiliate IOU. This is because some CCA member communities choose to automatically enroll their customers into their electricity with the most renewable energy, which is often slightly more expensive than the IOUs' default electricity product. These communities with slightly higher rates are all members of the Clean Power Alliance, and have a default electricity product with $50 \%$ renewable energy, 15 percentage points more than the default product offered by their affiliate IOU, Southern California Edison, in 2019 (California Energy Commission 2020). Only 8\% of CCA member communities (15 out of 182) have a default rate $1.5 \%$ to $8.6 \%$ more expensive than the affiliate IOU. This is because the majority of these communities have chosen the $100 \%$ renewable energy product as their default. ${ }^{14}$

While not always the CCA's default electricity product, all CCAs' lowest-cost electricity products are currently cheaper than their affiliate IOU's default electricity product. Similarly, when comparing electricity products with similar amounts of renewable energy between CCAs and IOUs, CCAs' electricity product is typically lower cost (i.e., a CCA's $100 \%$ renewable option is lower cost than the IOU's $100 \%$ renewable option). In the next section, we will describe additional reasons, beyond CCA rate-setting authority, that explain these rate differences.

CCAs can provide cleaner electricity at a lower rate than IOUs for a number of reasons, despite being smaller and therefore having less of an economies of scale advantage. First, the price of renewable energy has dropped rapidly over the last few decades (IRENA 2020), enabling CCAs to purchase it at a lower price. IOUs bought long-term renewable energy contracts prior to the launch of CCAs, when renewable energy was more expensive (DeShazo et al. 2017). However, CCA customers do pay fees to the IOU for some of the costs associated with these long-term renewable

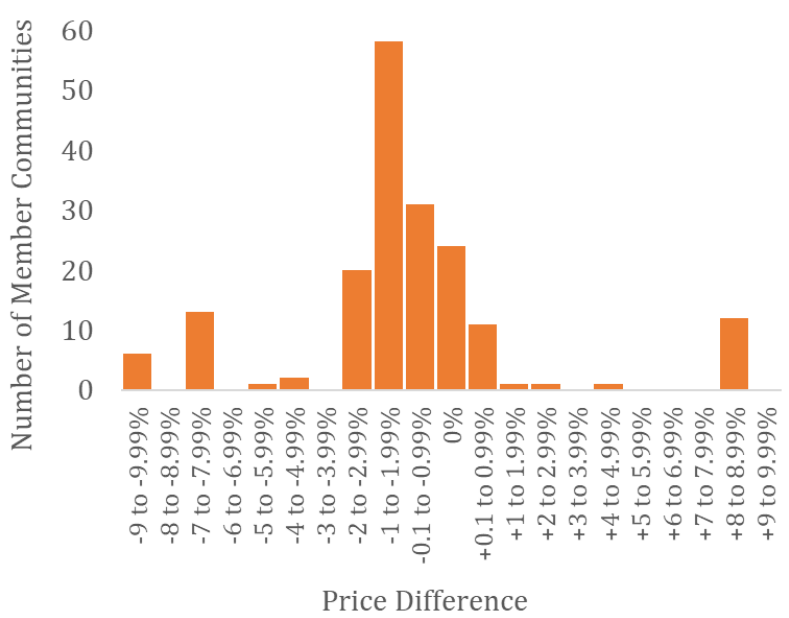

Figure 11: The distribution of CCA member communities' default rate compared to the affiliate IOU's default rate. Figure created by UCLA Luskin Center for Innovation. Data from each Joint Rate Comparison for each CCA and their affiliate IOU. All rates are accurate as of time of analysis in April 2020.

energy contracts. While CCA rates tend to be more stable, these fees have historically been volatile, which can make it challenging for CCAs to provide cost competitive energy (DeShazo et al. 2017). This is discussed further in section VI.i.

Second, as not-for-profit entities, CCAs have no shareholders and less overhead. Some note that this also gives them the advantage of cheaper financing (Chaset 2019) (DeShazo et al. 2017). Third, CCAs have an active market incentive to bargain harder to keep costs low. IOUs can pass through costs to customers with CPUC approval, so they have less of an incentive to keep costs low. Finally, many CCAs choose to invest a portion of net revenues into rate stabilization funds. These factors combine to create a cost advantage for CCAs in California that allows them to procure higher amounts of renewable energy while remaining competitive.

The use of unbundled renewable energy certificates can also affect an electricity provider's power supply costs but are not used frequently by California CCAs. Unbundled renewable energy certificates (RECs) are a "credit" for a unit of renewable energy generation that is purchased separately from the underlying

14 Twelve of the 13 communities with a more expensive default rate have a $100 \%$ renewable energy default electricity product. The remaining community is Palm Springs, which has a default electricity product with $50 \%$ renewable energy, for a total of $100 \%$ clean energy. 
electricity. Their use has been critiqued as entities typically still need to purchase electricity from dirtier generation resources, since the unbundled RECs do not come coupled with actual electricity. In California, there are limits on an electricity provider's use of unbundled RECs. California CCAs generally use fewer unbundled RECs over time, and seven CCAs have never used any unbundled RECs (Trumbull et al. 2019a).

\section{Ensuring sufficient funds to offer local energy programs}

The third primary way CCAs can provide additional value to customers is through offering local energy programs that support both environmental goals and customer retention, an important factor for a CCA's financial health.

CCAs have invested in a number of such innovative local energy programs. These typically provide financial and/or environmental benefits to customers and the community. They include rooftop solar and battery energy storage incentives, electrification, energy efficiency incentives, electric vehicle rebates, education, and more (CalCCA 2020c). Given CCAs' local nature, they are well-positioned to provide programs that reflect the unique preferences and needs of their communities. For example, MCE has a Low Income Families \& Tenants (LIFT) Program that provides energy and water efficiency assessments and rebates to low-income renters and owners of multifamily housing (MCE 2020b).

CCAs have also used local energy programs to respond to natural disasters and crises in their communities. For example, customers in two Northern California CCAs (MCE and Sonoma Clean Power) were directly impacted by destructive wildfires in 2017 and 2019. These CCAs created Advanced Energy Rebuild, programs that offered incentives to include energy efficient technologies and renewable energy when rebuilding homes destroyed by wildfires (MCE 2020c) (Sonoma Clean Power 2020).

In 2020, some CCAs created financial assistance programs in response to the COVID-19 pandemic. To directly alleviate some of the financial stress brought on by the pandemic, CCAs including Clean Power Alliance (Clean Power Alliance 2020), Peninsula Clean Energy (Daily Journal 2020), and Silicon Valley
Clean Energy (Silicon Valley Clean Energy 2020b), offered bill credits to low-income customers. Some CCAs, including East Bay Community Energy (East Bay Community Energy 2020), Sonoma Clean Power (CalCCA 2020b), and Valley Clean Energy (Valley Clean Energy 2020), have donated money to food banks, and more. CCAs may vary in the number and type of programs for a variety of reasons. For example, CCAs tend to offer more programs as they mature. CCAs that have recently launched may have fewer available revenues or capacity to administer such programs. Other reasons include differing local preference in program type and avoiding duplication of IOU programs available to CCA customers.

CCAs primarily fund local energy programs through their revenues. As public entities, CCAs are not-forprofit, so they reinvest any net revenues from electricity sales back into the community. CCA spending on these programs varies, but in exercising their rate-setting authority, CCAs can set rates sufficiently high to have more net revenues to reinvest in these programs but must balance that with the goal of keeping rates competitive with the affiliate IOU.

Reinvestment in local energy programs is influenced in part by California Proposition 26, which has been interpreted to apply to how CCA revenues can be spent. A report by Gridworks notes, "CCAs may be constrained from providing certain cross-subsidies by the provisions of Proposition 26, which does not apply to IOUs" (GridWorks 2018). One CCA feasibility study notes, "It is widely held that Proposition 26 (2010) prohibits the use of these reserves for any non-CCA related activity. The accumulated reserves and new program accruals present the new CCA with a large amount of funding and numerous opportunities going forward" (Coachella Valley Association of Governments Technical Advisory Committee 2016).

However, CCAs are not limited to using net margins from revenues to support local energy programs. For example, as part of their energy procurement, CCAs can invest directly in local electricity generation resources, such as solar or biomass facilities within their communities. CCAs can also leverage their position as a local, public entity to establish publicprivate partnerships to fund local energy programs. 
Beyond providing customers with financial and environmental benefits, local energy programs benefit the administering CCA. As noted above, local energy programs can help a CCA retain customers. For example, most CCAs offer their customers higher rooftop solar incentives through their net energy metering program (DeShazo 2018). This perk could persuade a customer to remain with the CCA.

Local energy programs provide another marketing advantage to CCAs, in addition to the power sources in their electricity product. These programs can be another way CCAs can differentiate themselves from IOUs. Per Senate Bill 100 (2018), all electricity providers in California will supply $100 \%$ carbon-free energy by 2045 . While CCAs can still differentiate by their choice in electricity resources (i.e., some customers have a preference for solar power over nuclear, or locally generated power versus out-ofstate), CCAs can also compete on their provision of attractive local energy programs to help them retain customers.

VI. Policy and regulatory considerations that affect CCAs ability to support environmental goals To understand how CCAs can advance environmental goals, we must recognize the broader policy context in which they operate. CCAs must comply with state policies, which can support or inhibit CCAs' ability to purchase carbon-free energy for customers and provide local energy programs. In this section, we examine three California policies and their implications for CCAs:

- Renewables portfolio standard (RPS)

- Resource adequacy

- IOU Code of Conduct

These policies affect CCAs' ability to procure carbonfree energy in a variety of ways. The state's renewables portfolio standard (RPS) has been a key policy to support renewable energy. ${ }^{15}$ CCAs have been a significant driver in accelerating the policy's goals. However, the RPS contract length requirements have implications for CCAs' resource procurement decisions and their ability to remain cost competitive. Similarly, a recent change to resource adequacy regulations poses limitations on some CCA energy procurement authority. Finally, a discussion of the IOU Code of Conduct and its importance in addressing threats to CCAs' market entry is included. These policies and their implications for how CCAs can advance environmental goals are discussed in this section.

The energy policy landscape in California is rapidly evolving, and this section is not intended to be comprehensive of all policies that affect CCAs and other electricity providers. However, this discussion covers recent issues that affect CCAs and how California has handled them to date. While these policies were established to support certain energy policy goals, it is important to consider how state policies can also create disadvantages or unintended consequences for CCAs' ability to meet environmental goals.

\section{i. Renewables Portfolio Standard: long-term contracts} and their implications for competition

A noteworthy component of California's RPS is the long-term contracting requirement. The previous iteration of the RPS, SB 350 (2015), requires that at least $65 \%$ of energy contracts used to meet RPS requirements must be for 10 years or longer (California 2015). This requirement has implications for CCA competitiveness and, subsequently, their ability to provide carbon-free energy to their customers competitively.

Signing long-term contracts is not necessarily a bad thing; on the contrary, it supports the construction of new renewable energy facilities that help fulfill California's renewable energy, climate, and reliability goals. However, this requirement affects CCA competitiveness in two ways. First, it inhibits the ability of electricity providers to take advantage of rapidly decreasing costs in renewables, as well as other future innovations in technology. Second, it increases the costs of customers switching between electricity providers.

Renewable energy costs have fallen rapidly, especially over the last decade. A recent report by the International Renewable Energy Agency found that from 2010 to 2019, solar photovoltaic costs decreased $82 \%$, onshore wind costs decreased 39\%, and offshore wind costs 29\% IRENA (2020). Being locked into long-term contracts limits CCAs' ability to purchase lower-cost carbon-free electricity

15 More information about RPS can be found in section III.i. 
generation as costs decrease, thereby restraining CCAs' efforts to keep rates low for customers.

Another important implication of these long-term contracts relates to a key component of the CCA authorizing legislation: maintaining customer indifference. ${ }^{16}$ This means that customers who remain with the IOU, particularly those who do not have a CCA option, are not financially affected by the customers who leave the IOU for the CCA. Because IOUs signed long-term contracts on behalf of customers who have since departed for CCAs, IOUs are left holding excess energy that is frequently more expensive than the cost of energy today. As described in section III.ii, this means that with the same amount of renewable energy for fewer customers, an IOU's per-customer share of renewable energy is increasing. However, IOUs still bear the costs of those long-term contracts, which were intended to be shared by all the customers they had at the time the contract was signed.

IOUs therefore recover these costs from departing customers in the form of "exit fees." These fees are charged to ensure that IOUs' remaining customers do not experience rate increases as a result of departing customers. California's solution to this challenge was the Power Charge Indifference Adjustment (PCIA). The fee is charged to CCA customers as a function of their electricity consumption. Numerous California Public Utilities Commission (CPUC) rulemakings have been opened to revise the calculation of the per-unit cost of the PCIA. Both the historical volatility and the projected increase in PCIA price provide challenges for CCAs in setting competitive rates.

Although IOUs can make up for lost costs with exit fees, there is currently no mechanism for CCAs to recover costs from their departing customers. When CCAs were relatively new, the CPUC expressed concerns regarding the lack of long-term power purchasing contracts in CCAs' portfolio, citing planning and reliability matters. But CCAs are now signing long-term contracts, too. For example, the oldest CCA, MCE, met $57 \%$ of its required renewable energy procurement with long-term contracts last year (California Public Utilities Commission 2020).
Considering a future with both more competition and more long-term renewable energy contracts raises questions that regulators and legislators need to address: How will electricity providers deal with increasing stranded costs as a result of customers moving between providers? Do current policies and regulations support or inhibit competition, innovation, and choice? Would local control over electricity policy better support renewable energy goals? Or would state-level or centralized decisionmaking and planning better mitigate challenges caused by long-term contracting requirements?

Regulators and legislators need to balance multiple goals: carbon-free energy, reliability, and competition. These goals are certainly not mutually exclusive. Supporting competition is not antirenewable. In fact, competition as a result of the emergence of CCAs has greatly supported renewable energy goals. And long-term contracts do not necessarily inhibit competition. However, policy alignment is critical to ensure that California's electricity sector goals do not contradict each other and that ratepayers subsequently do not bear the burden of misaligned policies.

\section{ii. Resource adequacy: changing regulation affects $C C A$ control over resources}

Currently, there are a few changes occurring to the CPUC's resource adequacy (RA) program that are consequential for CCA programs. Implemented after the energy crisis in the early 2000s, RA is the state's effort to ensure that there is sufficient capacity to maintain normal electrical grid operations. Under the program, some electricity providers, including CCAs and IOUs, submit reports demonstrating that they have procured sufficient energy capacity. Changes to California's energy landscape-notably the increasing dominance of renewable energy products, the growing diversity of electricity providers, and the expanding complexities of ensuring reliability in disparate localities throughout the state-are pushing the CPUC to make changes to its RA program that uniquely impact CCAs and their authority to make decisions about their energy resources.

Most recently, the CPUC approved a central buyer decision, which aims to address reliability concerns

\footnotetext{
${ }^{16}$ California Assembly Bill 117 (2002). "The bill would require a community choice aggregator to file an implementation plan with the Public Utilities Commission in order for the commission to determine a cost-recovery mechanism to be imposed on the community choice aggregator to prevent a shifting of costs to an electrical corporation's bundled customers."
} 
(California Public Utilities Commission 2020). The decision makes the state's two largest IOUs ${ }^{17}$ the central procurement entities for CCAs within their service territories. Currently, 22 of the 23 operational CCAs in the state are within these two IOUs' service territories. These IOUs will be responsible for local RA, one of the three types of required RA. While controversial, the CPUC notes that this will help maintain reliability and minimize the need for the California Independent System Operator (CAISO) to procure out-of-market energy products due to local deficiencies. 18

The state's CCAs argue that, in conferring this responsibility on the IOUs, the CPUC is infringing on their role in making energy procurement decisions on behalf of their customers. Importantly, while the decision sets a cap on local RA prices, IOUs procuring resources on behalf of CCA customers do not have the same incentives as CCAs do procuring on behalf of their own customers. First, CCAs are dependent on financial and resource decisions made by incumbent IOUs-decisions that may not reflect the preferences of CCA customers.

Second, requiring IOUs to procure on behalf of CCA customers may restrict a CCA's local autonomy in choosing which resources from which to supply RA. CCAs note that by having IOUs make RA procurement decisions on behalf of the CCA customers, localities lose their ability to choose what resources to invest in for RA, like battery energy storage. While the proposed decision is explicit in requiring that procurement decisions must consider other state policies, including reducing greenhouse gas emissions, IOUs may choose to not prioritize carbonfree energy the same way that CCAs typically do. For example, an IOU may decide to procure natural gas RA on behalf of the CCA, which opposes a CCA's goals for a greenhouse gas-free energy resource portfolio.

\section{iii. IOU code of conduct relative to CCAs}

One of the critical protections for CCAs is the IOU code of conduct relative to CCAs, established by SB 790 (2011). The bill required that the CPUC develop a code of conduct that would direct how incumbent IOUs would interact with newly formed CCAs. It was intended to ensure that CCAs were able to compete with other electricity providers on a "fair and equal basis" (California State Legislature 2011). It prohibits IOUs from actively marketing against emerging and existing CCAs. Specifically, incumbent IOUs cannot use ratepayer funds to lobby against CCAs. Instead, if IOUs want to market against these programs, they are required to form an independent marketing division, funded from shareholder revenues. Given that CCAs have taken on a significant portion of IOUs' retail electricity sales (California Public Utilities Commission 2017b), these agencies have been vocal in their criticism of this. However, the code of conduct has been essential at ensuring CCAs had a chance at market entry, thus enabling these entities to exist and provide their customers with carbon-free energy.

From a governance perspective, the code of conduct has been seen as necessary to ensure that CCAs are able to launch without undue lobbying against their efforts. When SB 790 was passed, legislators were concerned that local governments might be susceptible to intense IOU lobbying. Their concern was that locally elected officials would be less likely to support efforts to implement a CCA if the existing utility pushed back against the move. Given the relative power that utilities have, legislators were keen to ensure that these utilities did not prevent local efforts.

Furthermore, the code of conduct includes an area of common collaboration to guarantee that the state's ratepayers can make educated decisions about their choices for energy providers. Specifically, there has been an effort to advance information sharing. CCAs, for example, have a series of required pre-enrollment mailings, which let customers know that their service will be transferred to CCAs unless they decide to opt out. Yearly, CCAs and IOUs collaborate to send out joint rate comparisons, establishing the cost differential for different rate classes. This has a direct benefit for the state's ratepayers, who gain from obtaining factually correct information from both the CCAs and the IOUs.

\section{Conclusions and policy recommendations}

We find that California Assembly Bill 117 has been an effective policy at accelerating the transition to clean energy by enabling CCAs. This paper finds that CCAs have contributed significantly to the exceeding state

\footnotetext{
17 Pacific Gas \& Electric and Southern California Edison

18 Separately, the CAISO has being working to modify its own processes related to RA, including its own RA program through its RA enhancement process.
} 
renewable energy targets for both IOUs and CCAs over the past decade. The future contributions of CCAs to RPS over compliance are more uncertain and will depend on future RPS, CCA policies and regulation. First, much will depend on whether CCAs continue to grow their market share and demand levels of renewable energy in excess of RPS requirements. There is a possibility that the early CCA adopters were more focused on the goal of surpassing RPS requirements than will be later adopters. Several newer CCAs have focused more on maximizing the amount of carbon free electricity in their electricity portfolio, which is not always RPS-eligible, rather than exceeding state renewables requirements. However, given how CCAs have performed so far in contributing to exceeding state renewables requirements, supporting future CCA could help to continue this trend. Addressing policies and regulation that inhibit CCAs' competitiveness and ability to purchase renewable energy may help them continue to support clean energy goals going forward.

Second, in the long run, we expect IOUs to reduce current per-customer renewable energy holdings, bringing them closer to RPS requirements. We have already seen evidence that IOUs may sell off excess contracts, especially as an increasing amount of IOU load departs for CCAs. A current proceeding at the CPUC is considering how IOUs can reduce the excess renewable energy contracts in their portfolio (California Public Utilities Commission 2017a). If this occurs, IOU over compliance will decline. Potentially, those excess contracts could be purchased by CCAs, but shifting their ownership would not accelerate achieving RPS targets. IOUs may not have an incentive to keep the above-required levels of renewables in their portfolio without the state accelerating RPS compliance dates. As both IOUs and CCAs have shown they are capable of exceeding these interim targets, one potential solution to this is to set more ambitious interim RPS targets.

Regardless, as demonstrated in California, giving communities control over their electricity procurement decisions can help them achieve their environmental goals. CCAs' willingness to push beyond state minimum requirements for carbon-free energy can drive large and rapid greenhouse gas emissions reductions, while bringing other benefits to their communities such as tailored local energy programs, economic benefits, and more choice. As communities in other states explore tools to meet their environmental goals, many may consider CCAs as a solution.

States should consider how their policies and regulation inhibit or support a CCA's ability to purchase clean energy, invest in carbon-free energy resources, and invest in local energy programs that benefit their communities. One additional important regulatory consideration related to a CCA's energy procurement is whether the CCA is operating in a regulated or restructured electricity market. CCAs in restructured markets sign contracts with competitive suppliers, who then are responsible for purchasing electricity. CCAs in deregulated states sign contracts directly for electricity generation (O'Shaughnessy et al. 2019). In regulated electricity markets specifically, policies may attempt to ensure that remaining customers do not bear the costs of departing customers.

When pursuing environmental goals, those looking to develop CCAs should not forget the importance of maintaining financial health. A key way to support this, common across CCA-enabling legislation, is the automatic customer enrollment feature. Multicommunity collaboration in forming a CCA, as well as multi-CCA collaboration, can lead to additional economic benefits. Additionally, emerging CCAs should consider how they will offer additional value to their customers, especially by providing cheaper and cleaner electricity, and local energy programs to help retain customers. States looking to pass CCAenabling legislation in regulated electricity markets can also consider policies like California's IOU Code of Conduct, which supports market entry for new CCAs, as well as encourages competition across the electricity market by providing customers with information on their electricity choices.

We found CCAs have been implemented across a wide variety of customer demographics in California, suggesting that the CCA model can be replicable across many locations. However, communities with unmet local demand for renewable energy most effectively use the CCA model to support environmental goals. As seen in California, the ability to choose the default electricity product for customers is a key feature of this. CCA member 
communities can choose $100 \%$ carbon-free electricity for their customers.

While each state faces a unique electricity market and political context, the lessons learned from California's demographics, CCA design features, and policy and regulation can inform how CCAs can help these states advance their carbon-free energy goals.

\section{References}

"15-Day Report of Registration: February 18, 2020, for the March 3, 2020, Presidential Primary Election." California Secretary of State. Accessed 2020. https://www.sos.ca.gov/elections/reportregistration/15day-presprim-20

"2. Public Opinion on Renewables and Other Energy Sources." Pew Research Center, October 4, 2016. Accessed

2020. https://www.pewresearch.org/science/2016/10 104/public-opinion-on-renewables-and-otherenergy-sources/

"2019 Power Source Disclosure." California Energy Commission, 2020.

2019 RPS Compliance Reports. California Public Utilities Commission, 2020. "About CalCCA." CalCCA. Accessed 2020a. https://cal-cca.org/about/

"Advanced Energy Rebuild Napa." MCE. Accessed 2020c. https://www.mcecleanenergy.org/rebuildnapa/

"American Community Survey, 2010-2014 American Community Survey 5-Year Estimates, Table B19013." U.S. Census Bureau, 2020.

California Renewables Portfolio Standard Annual Report. California Public Utilities Commission, 2018.

"CCAs and COVID-19." CalCCA. Accessed 2020b. https://cal-cca.org/about/ccas-and-covid-19/

"CCA by State." Lean Energy U.S. Accessed 2020. https://www.leanenergyus.org/cca-by-state

"CCA Programs." CalCCA. Accessed 2020c. https://calcca.org/cca-programs/

"City and Town Population Totals: 2010-2019. Table Subcounty Resident Population Estimates: April 1, 2010 to July 1, 2019 (SUB-EST2019)." U.S. Census Bureau, 2020.

Chaset, Nick. "Myth of The Month: How Can CCA Rates Be Lower Than Investor Owned Utilities?" East Bay Community Energy, July 2, 2019. Accessed 2020. https://ebce.org/news-and-events/myth-of-themonth-how-can-cca-rates-be-lower-thaninvestor-owned-utilities/

Clean Energy and Pollution Reduction Act of 2015, Senate Bill $350 \quad$ (California 2015). https://leginfo.legislature.ca.gov/faces/billTextCl ient.xhtml?bill id=201520160SB350
"Community Choice Aggregation." U.S. Environmental Protection Agency. Accessed 2020. https://www.epa.gov/greenpower/communitychoice-aggregation

Community Choice Energy Programs: Existing and Prospective." Clean Power Exchange. Accessed 2020.

https://cleanpowerexchange.org/resources/pro grams/

"COVID-19 Resources." Clean Power Alliance, 2020. Accessed 2020. https://cleanpoweralliance.org/covid-19resources/

“COVID-19 Response." Silicon Valley Clean Energy, 2020b. Accessed 2020. https://www.svcleanenergy.org/covid-19/

Crume, Christina, and Lynette Green. Renewables Portfolio Standard Eligibility. 9th Revised ed. California Energy Commission, 2017. https://efiling.energy.ca.gov/getdocume nt.aspx?tn $=217317$

Daily Journal staff report. "Peninsula Clean Energy Grants $\$ 100$ Credit to Enrollees." The Daily Journal, March 31, 2020. https://www.smdailyjournal.com/news/local/pe ninsula-clean-energy-grants-100-credit-toenrollees/article d0a94da2-72eb-11ea-a85feb9c729cf035.html

DeShazo, J.R., Julien Gattaciecca, and Kelly Trumbull. Rep. The Growth in Community Choice Aggregation: Impacts to California's Grid. Los Angeles, California: UCLA Luskin Center for Innovation, 2018. https://innovation.luskin.ucla.edu/wpcontent/uploads/2019/03/The Growth in Com munity Choice Aggregation.pdf

DeShazo, J.R., Julien Gattaciecca, and Kelly Trumbull. Rep. The Promises and Challenges of Community Choice Aggregation in California. Los Angeles, California: UCLA Luskin Center for Innovation, 2017. https://innovation.luskin.ucla.edu/wpcontent/uploads/2019/03/The Promises and C hallenges of Community Choice Aggregation in CA.pdf

Electricity: community choice aggregation, Senate Bill 790 (California 2011). https://leginfo.legislature.ca.gov/faces/billTextCl ient.xhtml?bill_id=201120120SB790 
Electrical restructuring: aggregation, Assembly Bill 117. (California 2002).

http://www.leginfo.ca.gov/pub/01-

02/bill/asm/ab 01010150/ab 117 bill 20020924 chaptered.pdf

"Energy Savings for Multifamily Properties." MCE. Accessed 2020b. https://www.mcecleanenergy.org/multifamilysavings/

Gustafson, Abel, Matthew Goldberg, Seth Rosenthal, John Kotcher, Edward Maibach, and Anthony Leiserowitz. "Who Is Willing to Pay More for Renewable Energy?" Yale Program on Climate Change Communication, July 16, 2019. Accessed 2020.

https://climatecommunication.yale.edu/publicat ions/who-is-willing-to-pay-more-for-renewableenergy/

IRENA. Rep. Renewable Power Generation Costs in 2019. Abu Dhabi, United Arab Emirates: International Renewable Energy Agency, 2020. https://www.irena.org/Lmedia/Files/IRENA/Agency/Publication/2020/ Iun/IRENA Power Generation Costs 2019.pdf

Leiserowitz, Anthony, Edward Maibach, Seth Rosenthal, John Kotcher, Abel Gustafson, Parrish Ballew, and Matthew Goldberg. Rep. Energy in the American Mind: December 2018. Yale University and George Mason University. New Haven, CT: Yale Program on Climate Change Communication, 2018. DOI: 10.17605/OSF.IO/BDQ25

https://climatecommunication.yale.edu/wpcontent/uploads/2019/02/Energy-AmericanMind-December-2018.pdf

"Local Sol 100\% Locally-Produced Solar Energy." MCE. Accessed $2020 \mathrm{a}$ https://www.mcecleanenergy.org/100-localsolar/

"MBCP and SVCE Sign Contracts for $210 \mathrm{MW}$ of Geothermal and Solar Energy in California." Silicon Valley Clean Energy, April 21, 2020a. Accessed 2020. https://www.svcleanenergy.org/news/mbcpand-svce-sign-contracts-for-210-mw-ofgeothermal-and-solar-energy-in-california/

O'Shaughnessy, Eric, Emily Heeter, Julien Gattaciecca, Jenny Sauer, Kelly Trumbull, and Emily Chen. Rep. Community Choice Aggregation: Challenges, Opportunities, and Impacts on Renewable Energy Markets NREL/TP-6A20-72195. Golden, Colorado: National Renewable Energy Laboratory, 2019. https://www.nrel.gov/docs/fy19osti/72195.pdf

"Our Response to COVID-19." East Bay Community Energy, 2020. Accessed 2020. https://ebce.org/covid-19response/

PCIA Rulemaking 17-06-026. California Public Utilities Commission, 2017a.
Pacific Gas \& Electric and King City Community Power, 2020. "PG\&E - King City Community Power Joint Rate Comparisons."

Pacific Gas \& Electric and Pioneer Community Energy, 2020. "PG\&E - Pioneer Joint Rate Comparisons."

"Power Source Disclosure Program." California Energy Commission. Accessed 2020. https://www.energy.ca.gov/programs-andtopics/programs/power-source-disclosure

Pacific Gas and Electric and East Bay Community Energy, 2020.

https://res.cloudinary.com/diactiwk7/image/up load/fl sanitize, q auto/ebce-web-comparisonmay2020-new-ebce-bill-format-2.pdf

"Providing you with $\$ 17,500$ to rebuild an efficient, sustainable home." Sonoma Clean Power. Accessed 2020. https://sonomacleanpower.org/programs/advan ced-energy-rebuild

Rep. Community Choice Aggregation and California's Clean Energy Future. Oakland, California: Gridworks, 2018. https://gridworks.org/wpcontent/uploads/2018/06/Gridworks CCAClean-Energy-Overview final-1.pdf

Rulemaking. 17-09-020. Decision on Central Procurement of the Resource Adequacy Program. California Public Utilities Commission, 2020.

Staff report. "Community Choice Aggregation: Business Plan/Feasibility Study Update." Coachella Valley Association of Governments Technical Advisory Committee, 2016.

Staff White Paper. Consumer and Retail Choice, the Role of the Utility, and an Evolving Regulatory Framework. California Public Utilities Commission, 2017b.

Silicon Valley Clean Energy Authority Board of Directors Meeting Agenda Packet. Silicon Valley Clean Energy, 2019.

SCE and CPA Joint Rate Comparison. Southern California Edison and Clean Power Alliance, 2020. https://cleanpoweralliance.org/wpcontent/uploads/2020/06/SCE-and-CPA-JointRate-Comparison-May-2020-2018-Vintage.pdf

Trumbull, Kelly, Colleen Callahan, Sarah Goldmuntz, and Michelle Einstein. Rep. Progress Toward 100\% Clean Energy in Cities \& States Across the U.S. Los Angeles, California: UCLA Luskin Center for Innovation, 2019. https://innovation.luskin.ucla.edu/wpcontent/uploads/2019/11/100-Clean-EnergyProgress-Report-UCLA-2.pdf 
Trumbull, Kelly, J.R. DeShazo, Julien Gattaciecca, Michelle Einstein, and Colleen Callahan. Rep. The Rapid Growth in Community Choice Energy and Its Acceleration of Renewable Energy: A California Case Study. Los Angeles, California: UCLA Luskin Center for Innovation, 2019a. https://innovation.luskin.ucla.edu/wpcontent/uploads/2019/11/Rapid Growth of Co mmunity Choice Energy.pdf
"VCE donates to Yolo Food Bank." Valley Clean Energy, March 2020. Accessed 2020. https://valleycleanenergy.org/news/yolo-foodbank-press-release/

Your New Electricity Provider. Monterey, California: Monterey Bay Community Energy, 2018. https://monterey.org/Portals/0/FAQs/MBCPFact-Sheet-FINAL-v10.pdf

Kelly Trumbull is a project manager at the UCLA Luskin Center for Innovation. Her research supports the Center's energy, water, and climate initiatives. She graduated with a Master of Public Policy from the UCLA Luskin School of Public Affairs and received a Global Environment and Resources Certificate from UCLA's Global Public Affairs Program. She holds a B.A. in Political Science with a concentration in comparative politics from the University of California, Santa Barbara.

J.R. DeShazo is the Director of the UCLA Luskin Center for Innovation. He also is a Professor of Public Policy in the UCLA Luskin School of Public Affairs. He holds a Ph.D. in Urban Planning from Harvard University and a M.Sc. in Development Economics from Oxford University, where he was a Rhodes Scholar. He is co-chair of the External Environmental Economics Advisory Committee, an independent organization providing the best available economic advice to the U.S. Environmental Protection Agency.

\section{Acknowledgments}

We thank Michael Northrop and Deborah Burke. We also thank Tyler Aguirre, Woody Hastings, Gordian Raacke, and CC Song who generously contributed their time to review the paper. This report could not have been completed without Julien Gattaciecca and Sarah Goldmuntz whose assistance supported this paper. Thank you to Colleen Callahan, Nick Cuccia, and Michelle Einstein for their review. 